T. Methling, M. Braun-Unkhoff, U. Riedel, An Optimised Chemical Kinetic Model for the Combustion of Fuel Mixtures of Syngas and Natural Gas, Fuel 262 (2020) 116611.

The original publication is available at www.elsevier.com

http://dx.doi.org/10.1016/j.fuel.2019.116611

(C) 2020. This manuscript version is made available under the CC-BY-NC-ND

4.0 license http://creativecommons.org/licenses/by-nc-nd/4.0/ 


\title{
An Optimised Chemical Kinetic Model for the Combustion of Fuel Mixtures of Syngas and Natural Gas
}

\author{
T. Methling ${ }^{\mathrm{a}, *}$, M. Braun-Unkhoff ${ }^{\mathrm{a}}$, U. Riedel ${ }^{\mathrm{a}}$ \\ ${ }^{a}$ German Aerospace Center (DLR), Institute of Combustion Technology, 70569 Stuttgart, \\ Germany
}

\begin{abstract}
A chemical kinetic model for the combustion of fuel mixtures - mainly of hydrogen, carbon monoxide and methane - was derived from a comprehensive optimisation based on experimental data. The experimental data include ignition delay times from shock tubes, species profiles from shock tubes, jet stirred reactors, flow reactors and burner stabilised flames as well as several laminar flame speeds. For this large scale optimisation of 475 model parameters within their uncertainty boundaries the novel linear transformation model was successfully applied. The derived optimised chemical kinetic model reproduces the experimental data significantly more accurately than established conventional models that are also investigated in this study. In this regard, especially the reproducibility of the experiments for the combustion of fuel mixtures containing both syngas and methane is significantly increased. The chemical kinetic model is valid for a wide range of boundary conditions and is suitable for the numerical design and adaptation of various combustion machinery running on the investigated fuel mixtures or biogenic
\end{abstract}

\footnotetext{
*Corresponding author:

Email address: torsten.methling@dlr.de (T. Methling)
} 
gases, respectively.

Keywords:

chemical kinetic model, syngas, natural gas, biogenic fuel, optimisation

\section{Introduction}

The accurate chemical kinetic modelling of $\mathrm{H}_{2}, \mathrm{CO}$ and $\mathrm{CH}_{4}$ combustion 3 is of vast importance. On the one hand these fuel components are typical for 4 biogenic gas mixtures, which gain more attention for combustion machinery 5 and are for instance utilised in decentralised power generation. On the other hand the combustion model of these components is the basis of any chemical kinetic model of more complex hydrocarbons. Thus, accurate chemical kinetic models are required for sophisticated designs of combustion machinery to guarantee reliable and safe operation of the machinery at low pollutant oped for the combustion of syngas and methane (e.g. [1-3]), these models still show some discrepancies on the numerical reproduction of many fundamental experiments, especially for fuel mixtures of syngas and methane, e.g. for shock tubes [4], for jet stirred reactors [5] or laminar burners [6]. A reason for these discrepancies can be certain chemical kinetic processes that are not fully included in the current models, which can lead to systematic errors in simulations. An example of such processes are reactions forming $\mathrm{HCO}$. HCO has a relatively low dissociation threshold. As a consequence, the timescales of vibrational and rotational relaxation and dissociation are comparable [7]. This can lead to a prompt dissociation of HCO radicals formed by reactions, which can have a strong influence on chemical kinetic processes and signifi- 
cantly impact combustion characteristics like laminar flame speeds [7, 8].

Another main reason for model deficiencies is the large number of hundreds or thousands of model parameters - mainly parameters of reaction rate coefficients - and their uncertainties from the direct determination of the parameter coefficients via experiments or numerical simulations [9]. To improve the chemical kinetic models, hyperdimensional model optimisations based on large data sets derived from combustion experiments can be applied. Thereby, extensive optimisations of chemical kinetic models were successfully performed and documented in the literature, e.g. for the combustion of hydrogen [10-12], syngas [13] or natural gas [1, 14]. These optimisations were mainly based on response surface methods, which approximate the solution space of the hyperdimensional model parameters by polynomials. For this approximation a large number of randomised model parameter sets need to be evaluated. Thereby, the computational costs of this approximation increases exponentially with the number of optimised model parameters, drastically limiting the efficiency of research in this field of optimisation. To overcome this limitation, the novel linear transformation model (linTM) can be applied [15]. With the linTM the relations between model parameters and output parameters of the solution space are linearised, at the same time keeping a high accuracy of this linear approximation. Hereby, the numerical costs are radically decreased compared to conventional methods, as the increase of the numerical costs is not exponentially but linearly dependent on the number of optimised model parameters. This approach is very general and can be applied with data from various fundamental experiments and for a broad variety of fuels. 
The objective of this work is the optimisation of a large number of chemical kinetic model parameters (more than 400) to increase the reproducibility of experimental results from the combustion of fuel mixtures, consisting mainly of syngas and methane. Hereby, model parameters are optimised within their uncertainty limits gained from literature. With the optimisation, a wide range of experimental data was targeted, including ignition delay times, species profiles and laminar flame speeds. Indications are given towards modelling directions for further investigation on certain reaction rate coefficients. Though, one major drawback of these optimisation processes is the inability to detect or account for systematic errors. A past example of these errors from models is the afore mentioned prompt dissociation of HCO. Due to the complexity and high number of model parameters in chemical kinetic models for the investigated combustion processes, the reduction of uncertainty bands of rate coefficients is not a major objective of this work. Thus, the main purpose of the optimised model is to increase the prediction accuracy e.g. of CFD simulations for the design and adaptation of applied reliable combustion machinery at low pollutant emission levels.

\section{Optimisation Method}

The linear transformation model (linTM) - including its optimisation method - is described in detail in prior work [15] and is only reviewed briefly here. The linTM mainly consists of two basic concepts. On the one hand the Arrhenius coefficients are substituted by a set of three different input parameters. In detail the first two parameters to represent the Arrhenius equation are two deviations from the original rate coefficient at two different temper- 
atures $\Delta \lg \left(k\left(T_{1}\right)\right)$ and $\Delta \lg \left(k\left(T_{2}\right)\right)$. In addition, for the full parametrisation of the Arrhenius equation a third parameter is required. This parameter is either a third deviation of the original rate coefficient $\Delta \lg \left(k\left(T_{3}\right)\right)$ or a deviation from the original activation energy $\Delta E_{\mathrm{A}}$. With this substitution, the dependencies of the input parameters on each other are decoupled. To simplify the mathematical notations, all input parameters are represented by normalised variables $\tau_{i}$. On the other hand species profiles (as a function of time, distance or temperature) or laminar flame speed profiles (as a function of the fuel-air equivalence ratio $\varphi$ ) are defined by coordinates of characteristic points $(\mathrm{CP})$, e.g. the maximum of an intermediate or the point where $50 \%$ of the maximum value is reached. Hereby, experiment and simulation results are compared by distances $d_{j}$ between these coordinates or the quantities $q$, respectively:

$$
d_{j}=\ln \left(\frac{q_{j, \text { simulation }}}{q_{j, \text { experiment }}}\right) .
$$

With the linTM the relations between the input parameters and the distances between the coordinates $d_{j}$ are linearised, thereby, keeping a high accuracy. These simplified linear relations can be efficiently used for the global sensitivity analysis and optimisation of chemical kinetic models. Specifically, for the optimisation, a gradient based solver is applied, using the method of least squares to minimise the distances $d_{j}$. For this minimisation, the objective function $F$ is:

$$
F=\sum_{j=1}^{D}\left(w_{j} d_{j}\right)^{2},
$$

for which, $D$ is the total number of distances. In Eq. (2), the distances are additionally weighted with a weighting factor $w_{j}$.

For the sensitivity analysis of a reaction $r$ on the experimental set, we 
use the definition of the global sensitivity $S_{r}$ of the linTM [15]:

$$
S_{r}=\sum_{j=1}^{D} S_{r, j}=\sum_{j=1}^{D}\left(\sum_{i=m}^{m+P_{r}-1}\left(w_{j} \frac{\partial d_{j}}{\partial \tau_{i}}\right)^{2}\right)^{0.5}
$$

In this equation $S_{r}$ is the sum of the sensitivities of each reaction $r$ on each distance $d_{j}$. Thereby, $P_{r}$ is the total number of input parameters $\tau_{i}$ belonging to reaction $r$.

\section{Selection of Experimental Data}

The set of experimental targets for the optimisation process was built from ignition delay times and species profiles from shock tubes (ST), jet stirred reactors (JSR), flow reactors (FR) and burner stabilised flames (BF), and from laminar flame speeds (FS). In this study, experimental data from rapid compression machines (RCM) and species profiles in low pressure flames that were collected in situ by probes were not included. The reasons for excluding RCM data, are ongoing investigations showing a high sensitivity of the RCM design on the measured data (e.g. [16, 17]), resulting in highly spread data for the same conditions from different devices. The reasons for excluding the data from the low pressure flames are ongoing studies on the impact of the probe on the flow and temperature field of the flames and consequently on the measured species profiles $[18,19]$. In general, these two types of experiments offer very useful insights into chemical kinetics. But for their implementation into optimisation processes, further investigations are required to fully understand their uncertainties.

The fuel-air equivalence ratio $\varphi$ and the range of pressure $p$ of the experiments from ST, FR and JSR are listed in Tables 1 and 2. The targeted flame 
Table 1: List of shock tube experiments utilised for optimisation

\begin{tabular}{|c|c|c|c|c|c|}
\hline Fuel (molar) & $\varphi$ & Bath gas & $p /$ bar & No. of $q$ & Ref. \\
\hline \multicolumn{6}{|l|}{ Shock tube (ST), ignition delay times } \\
\hline $\mathrm{H}_{2} / \mathrm{CO}=5 / 95$ & 1.0 & Ar & $1-16$ & 23 & {$[20]$} \\
\hline $\mathrm{H}_{2} / \mathrm{CO}=5 / 95$ & 0.5 & $\mathrm{~N}_{2}$ & $1-19$ & 48 & {$[21]$} \\
\hline $\mathrm{H}_{2} / \mathrm{CO}=10 / 90$ & 0.5 & $\mathrm{~N}_{2}$ & $1-17$ & 30 & {$[21]$} \\
\hline $\mathrm{H}_{2} / \mathrm{CO}=20 / 80$ & 0.5 & $\mathrm{~N}_{2}$ & $1-18$ & 24 & {$[21]$} \\
\hline $\mathrm{H}_{2} / \mathrm{CO}=26 / 74$ & 1.0 & Ar $; \mathrm{N}_{2}$ & $2-20$ & 30 & {$[22]$} \\
\hline $\mathrm{H}_{2} / \mathrm{CO}=33 / 67$ & 1.0 & $\operatorname{Ar}$ & $2-20$ & 28 & {$[22]$} \\
\hline $\mathrm{H}_{2} / \mathrm{CO}=50 / 50$ & 1.0 & $\mathrm{Ar}$ & $1-16$ & 20 & {$[20]$} \\
\hline $\mathrm{H}_{2} / \mathrm{CO}=50 / 50$ & 1.0 & $\mathrm{Ar} ; \mathrm{CO}_{2}$ & $2-20$ & 30 & {$[22]$} \\
\hline $\mathrm{H}_{2} / \mathrm{CO}=70 / 30$ & 1.0 & $\mathrm{Ar}$ & $2-20$ & 35 & {$[22]$} \\
\hline $\mathrm{CH}_{3} \mathrm{OH}$ & 1.0 & $\mathrm{Ar}$ & $1-16$ & 15 & {$[23]$} \\
\hline $\mathrm{CH}_{4}$ & 0.5 & $\mathrm{Ar}$ & $1-8$ & 6 & {$[24]$} \\
\hline $\mathrm{CH}_{4}$ & 2.0 & $\mathrm{~N}_{2} ; \mathrm{CO}_{2}$ & $1-10$ & 35 & {$[25]$} \\
\hline $\mathrm{CH}_{4}$ & 2.0 & $\mathrm{Ar} ; \mathrm{CO}_{2}$ & 1 & 6 & {$[26]$} \\
\hline $\mathrm{C}_{2} \mathrm{H}_{2}$ & $0.5 ; 1.0$ & $\mathrm{Ar}$ & 1 & 33 & {$[27]$} \\
\hline $\mathrm{C}_{2} \mathrm{H}_{2}$ & $0.5-2.0$ & $\mathrm{~N}_{2} ; \mathrm{Ar}$ & $10-30$ & 38 & {$[28]$} \\
\hline $\mathrm{C}_{2} \mathrm{H}_{4}$ & 1.0 & $\mathrm{Ar}$ & 1 & 8 & [29] \\
\hline $\mathrm{C}_{2} \mathrm{H}_{6}$ & $0.5 ; 1.0$ & $\mathrm{Ar}$ & 1 & 17 & [30] \\
\hline \multicolumn{6}{|l|}{ Shock tube (ST), OH* and $\mathrm{CH}^{*}$ profiles } \\
\hline $\mathrm{CH}_{4}$ & $0.5 ; 1.0$ & $\operatorname{Ar}$ & $1-16$ & 242 & {$[31]$} \\
\hline $\mathrm{RG}=\mathrm{CH}_{4} / \mathrm{C}_{2} \mathrm{H}_{6}=92 / 8$ & 1.0 & $\mathrm{Ar}$ & $1-16$ & 189 & {$[32]$} \\
\hline $\mathrm{H}_{2} / \mathrm{RG}=40 / 60$ & $0.5 ; 1.0$ & $\operatorname{Ar}$ & $1-16$ & 540 & {$[32]$} \\
\hline $\mathrm{H}_{2} / \mathrm{RG}=80 / 20$ & $0.5 ; 1.0$ & $\operatorname{Ar}$ & $1-16$ & 454 & {$[32]$} \\
\hline $\mathrm{CO} / \mathrm{RG} / \mathrm{CO}_{2}=25.3 / 11.4 / 63.3$ & 1.0 & $\operatorname{Ar}$ & 16 & 30 & {$[33]$} \\
\hline $\mathrm{CO} / \mathrm{RG} / \mathrm{CO}_{2}=61.9 / 5.6 / 32.5$ & 1.0 & $\operatorname{Ar}$ & 16 & 33 & {$[33]$} \\
\hline $\mathrm{H}_{2} / \mathrm{CO} / \mathrm{CH}_{4} / \mathrm{CO}_{2}=5 / 31 / 38 / 26$ & $0.5 ; 1.0$ & $\mathrm{Ar}$ & 4 & 330 & {$[31]$} \\
\hline
\end{tabular}

speed measurements are listed in Table 3. Additionally combustion experiments of $\mathrm{C}_{2} \mathrm{H}_{2}, \mathrm{C}_{2} \mathrm{H}_{4}$ and $\mathrm{C}_{2} \mathrm{H}_{6}$ were added to the experimental data set. These components are important intermediates for the fuel rich combustion of methane and at the same time are typical minor components of natural gas, relevant for various applied combustion systems.

The ignition delay times were defined by measurements of photon emissions from excited $\mathrm{OH}$ or $\mathrm{CH}$ radicals. Thereby, they were defined by the maximum emission (e.g. [20]) or by the intersection method (e.g. [29]). If 
Table 2: List of flow reactor, jet stirred reactor and burner stabilised flame experiments utilised for optimisation

\begin{tabular}{lccccc}
\hline Fuel (molar) & $\varphi$ & Bath gas & $p /$ bar & No. of $q$ & Ref. \\
\hline Flow reactor (FR) & & & & & \\
$\quad \mathrm{H}_{2}$ & $0.3-1.0$ & $\mathrm{~N}_{2}$ & $0.3-16$ & 28 & {$[34]$} \\
$\mathrm{CO}$ & 1.0 & $\mathrm{~N}_{2} ; \mathrm{H}_{2} \mathrm{O}$ & $3.5 ; 9.7$ & 6 & {$[35]$} \\
$\mathrm{CH}_{2} \mathrm{O}$ & $1 / 225-1 / 150$ & $\mathrm{~N}_{2} ; \mathrm{H}_{2} \mathrm{O}$ & $1.5 ; 9.7$ & 24 & {$[36]$} \\
$\mathrm{CH}_{4}$ & $0.5 ; 1.0 ; 2.0$ & $\mathrm{Ar}$ & 1 & 33 & {$[37]$} \\
$\mathrm{CH}_{4}$ & $0.06 ; 1.0 ; 19.7$ & $\mathrm{~N}_{2}$ & 100 & 35 & {$[38]$} \\
$\mathrm{C}_{2} \mathrm{H}_{2}$ & $1.0 ; 1.4$ & $\mathrm{~N}_{2}$ & 1 & 28 & {$[39]$} \\
$\mathrm{C}_{2} \mathrm{H}_{4}$ & $0.5 ; 1.0$ & $\mathrm{Ar}$ & 1 & 34 & {$[37]$} \\
$\mathrm{C}_{2} \mathrm{H}_{4}$ & 2.5 & $\mathrm{~N}_{2}$ & $5 ; 10$ & 33 & {$[40]$} \\
Jet stirred reactor (JSR) & & & & & \\
$\mathrm{H}_{2}$ & 0.2 & $\mathrm{~N}_{2}$ & 1 & 4 & {$[5]$} \\
$\mathrm{H}_{2} / \mathrm{CO}=50 / 50$ & 0.2 & $\mathrm{~N}_{2}$ & 1 & 6 & {$[41]$} \\
$\mathrm{CH}_{3} \mathrm{OH}$ & $0.5-2.0$ & $\mathrm{~N}_{2}$ & $1-20.3$ & 80 & {$[42]$} \\
$\mathrm{CH}_{4}$ & 0.1 & $\mathrm{~N}_{2}$ & 1 & 20 & {$[5]$} \\
$\mathrm{CH}_{4}$ & $0.1 ; 0.5 ; 1.0$ & $\mathrm{~N}_{2}$ & $1 ; 10$ & 50 & {$[43]$} \\
$\mathrm{CH}_{4}$ & 1.5 & $\mathrm{~N}_{2}$ & 10 & 18 & {$[44]$} \\
$\mathrm{H}_{2} / \mathrm{CH}=50 / 50$ & 0.3 & $\mathrm{~N}_{2} ; \mathrm{CO}_{2}$ & $1 ; 10$ & 71 & {$[5]$} \\
$\mathrm{H}_{2} / \mathrm{CH}=50 / 50$ & $1.0 ; 1.5$ & $\mathrm{~N}_{2} ; \mathrm{CO}_{2}$ & $1 ; 10$ & 61 & {$[44]$} \\
$\mathrm{H}_{2} / \mathrm{CO} / \mathrm{CH}_{4}=25 / 25 / 50$ & 0.3 & $\mathrm{~N}_{2}$ & 1 & 24 & {$[5]$} \\
$\mathrm{H}_{2} / \mathrm{CO} / \mathrm{CH}_{4}=25 / 25 / 50$ & 1.5 & $\mathrm{~N}_{2}$ & 1 & 18 & {$[44]$} \\
$\mathrm{C}_{2} \mathrm{H}_{2}$ & $0.4 ; 1.0$ & $\mathrm{~N}_{2}$ & 1 & 53 & {$[45]$} \\
Burner stabilised flame (BF) & & & & & {$[46,47]$} \\
$\mathrm{CH}_{4}$ & $1.0-1.9$ & $\mathrm{~N}_{2}$ & 0.039 & 26 & \\
\hline & & & & & \\
\hline
\end{tabular}

available the complete normalised emission profiles of $\mathrm{OH}$ and $\mathrm{CH}$ chemiluminescence from ST were selected as targets for the optimisation as shown in previous work [15]. The pressure profiles of the ST were taken as input values for the simulation. If these were not available we considered constant pressure until ignition occurs in the ST [31, 32]. More details on the selected pressure conditions are given in the Supplementary Materials. For the FR and JSR the reactants, products and intermediates $\left(\mathrm{CO}, \mathrm{CH}_{2} \mathrm{O}, \mathrm{C}_{2} \mathrm{H}_{2}\right.$, $\left.\mathrm{C}_{2} \mathrm{H}_{4}, \mathrm{C}_{2} \mathrm{H}_{6}\right)$ were targeted in the optimisation process. For the BF the intermediates $\mathrm{HCO}$ and singlet methylene ${ }^{1} \mathrm{CH}_{2}$ were targeted, which were 
Table 3: List of laminar flame speeds utilised for optimisation

\begin{tabular}{|c|c|c|c|}
\hline Fuel (molar) & $T_{0} / \mathrm{K}$ & $p /$ atm & Ref. \\
\hline $\mathrm{H}_{2}$ & 298 & 1 & {$[48]$} \\
\hline $\mathrm{H}_{2}$ & 298 & 1 & [49] \\
\hline $\mathrm{H}_{2} / \mathrm{N}_{2}=30 / 70$ & 298 & 1 & {$[50]$} \\
\hline $\mathrm{H}_{2} / \mathrm{N}_{2}=25 / 75$ & 298 & 1 & {$[50]$} \\
\hline $\mathrm{H}_{2} / \mathrm{N}_{2}=25 / 75$ & 298 & 1 & {$[51]$} \\
\hline $\mathrm{H}_{2} / \mathrm{CO}=50 / 50$ & 298 & 1 & {$[48]$} \\
\hline $\mathrm{H}_{2} / \mathrm{CO}=50 / 50$ & 298 & 2 & {$[52]$} \\
\hline $\mathrm{H}_{2} / \mathrm{CO} / \mathrm{N}_{2}=20 / 20 / 60$ & 302 & 1 & [53] \\
\hline $\mathrm{H}_{2} / \mathrm{CO} / \mathrm{N}_{2}=10 / 20 / 70$ & 298 & 1 & {$[50]$} \\
\hline $\mathrm{H}_{2} / \mathrm{CO} / \mathrm{N}_{2}=15 / 15 / 70$ & 298 & 1 & [50] \\
\hline $\mathrm{H}_{2} / \mathrm{CO} / \mathrm{N}_{2}=20 / 10 / 70$ & 298 & 1 & [53] \\
\hline $\mathrm{H}_{2} / \mathrm{CO} / \mathrm{N}_{2}=24 / 6 / 70$ & 298 & 1 & {$[50]$} \\
\hline $\mathrm{H}_{2} / \mathrm{CO} / \mathrm{CO}_{2}=12 / 48 / 40$ & 300 & 1 & {$[54]$} \\
\hline $\mathrm{H}_{2} / \mathrm{CO} / \mathrm{CO}_{2}=30 / 30 / 40$ & 300 & 1 & [54] \\
\hline $\mathrm{H}_{2} / \mathrm{CO} / \mathrm{CO}_{2}=5 / 45 / 50$ & 298 & 1 & {$[55]$} \\
\hline $\mathrm{H}_{2} / \mathrm{CO} / \mathrm{CO}_{2}=10 / 40 / 50$ & 303 & 1 & [54] \\
\hline $\mathrm{H}_{2} / \mathrm{CO} / \mathrm{CO}_{2}=25 / 25 / 50$ & 303 & 1 & {$[54]$} \\
\hline $\mathrm{H}_{2} / \mathrm{CO} / \mathrm{CO}_{2}=40 / 10 / 50$ & 303 & 1 & {$[54]$} \\
\hline $\mathrm{CH}_{3} \mathrm{OH}$ & 298 & 1 & {$[56]$} \\
\hline $\mathrm{CH}_{3} \mathrm{OH}$ & 338 & 1 & {$[56]$} \\
\hline $\mathrm{CH}_{4}$ & 342 & $0.1 ; 0.25$ & {$[8]$} \\
\hline $\mathrm{CH}_{4}{ }^{\mathrm{a}}$ & 298 & 1 & {$[57]$} \\
\hline $\mathrm{CH}_{4}$ & 298 & $1 ; 2 ; 4$ & {$[58]$} \\
\hline $\mathrm{CH}_{4}$ & 358 & 1 & {$[6]$} \\
\hline $\mathrm{H}_{2} / \mathrm{CH}_{4}=30 / 70$ & 298 & 1 & [59] \\
\hline $\mathrm{H}_{2} / \mathrm{CH}_{4}=35 / 65$ & 298 & 1 & {$[60]$} \\
\hline $\mathrm{H}_{2} / \mathrm{CH}_{4}=35 / 65$ & 298 & 1 & {$[61]$} \\
\hline $\mathrm{H}_{2} / \mathrm{CH}_{4}=40 / 60$ & 298 & 1 & [59] \\
\hline $\mathrm{H}_{2} / \mathrm{CH}_{4}=50 / 50$ & 298 & 1 & {$[60]$} \\
\hline $\mathrm{H}_{2} / \mathrm{CH}_{4}=80 / 20$ & 303 & 1 & {$[62]$} \\
\hline biogenic $\operatorname{mix} 1^{\mathrm{b}}$ & 298 & 1 & {$[6]$} \\
\hline biogenic mix $2^{c}$ & 298 & 1 & {$[6]$} \\
\hline $\mathrm{C}_{2} \mathrm{H}_{2}$ & 298 & 1 & {$[63]$} \\
\hline $\mathrm{C}_{2} \mathrm{H}_{4}$ & 298 & 1 & [63] \\
\hline $\mathrm{C}_{2} \mathrm{H}_{6}$ & 298 & 1 & [63] \\
\hline $\mathrm{H}_{2} / \mathrm{CH}_{4} / \mathrm{C}_{2} \mathrm{H}_{6}=35 / 52 / 13$ & 298 & 1 & {$[60]$} \\
\hline
\end{tabular}

${ }^{a}$ with argon in oxidiser

${ }^{\mathrm{b}} \mathrm{H}_{2} / \mathrm{CO} / \mathrm{CH}_{4} / \mathrm{CO}_{2} / \mathrm{N}_{2}=12 / 19 / 5.8 / 13.2 / 50$

${ }^{\mathrm{c}} \mathrm{H}_{2} / \mathrm{CO} / \mathrm{CH}_{4} / \mathrm{CO}_{2} / \mathrm{N}_{2}=9.6 / 15.2 / 24.6 / 10.6 / 40$ 


\section{Chemical Kinetic Model}

To create a base chemical kinetic model for the optimisation, the in-house model DLR-RG [3] was selected as the baseline model. The model was extended with a sub model for $\mathrm{C}_{3}$ species from the USC II mechanism [2], 
which was required to simulate the $\mathrm{C}_{2}$ oxidation - especially the laminar flame speeds. For the $\mathrm{C}_{2} \mathrm{H}_{2}$ oxidation vinylidene was added as an intermediate as suggested by Laskin and Wang [67]. As another major update for the simulation of the $\mathrm{C}_{2} \mathrm{H}_{2}$ oxidation - mainly of the JSR experiments - the multi channel reactions of triplet methylene radical and the vinyl radical with molecular oxygen needed to be updated:

$$
\begin{aligned}
& { }^{3} \mathrm{CH}_{2}+\mathrm{O}_{2} \rightleftharpoons \mathrm{CO}_{2}+\mathrm{H}_{2}, \\
& \rightleftharpoons \mathrm{CO}_{2}+\mathrm{H}+\mathrm{H} \\
& \rightleftharpoons \mathrm{CO}+\mathrm{H}_{2} \mathrm{O} \\
& \rightleftharpoons \mathrm{CO}+\mathrm{OH}+\mathrm{H} \\
& \rightleftharpoons \mathrm{CH}_{2} \mathrm{O}+\mathrm{O} \\
& \mathrm{C}_{2} \mathrm{H}_{3}+\mathrm{O}_{2} \rightleftharpoons \mathrm{CO}_{2}+\mathrm{CH}_{3} \\
& \rightleftharpoons \mathrm{CO}+\mathrm{CH}_{3} \mathrm{O} \\
& \rightleftharpoons \mathrm{CH}_{2} \mathrm{O}+\mathrm{HCO} \\
& \rightleftharpoons \mathrm{C}_{2} \mathrm{H}_{2}+\mathrm{HO}_{2} \\
& \rightleftharpoons \mathrm{CH}_{2} \mathrm{CHOO} \\
& \rightleftharpoons \mathrm{CH}_{2} \mathrm{CHO}+\mathrm{O} \\
& \rightleftharpoons \mathrm{CH}_{2} \mathrm{CO}+\mathrm{OH} \\
& \rightleftharpoons \mathrm{CHCHO}+\mathrm{OH} \\
& \rightleftharpoons \mathrm{CHOCHO}+\mathrm{H}
\end{aligned}
$$

154 Thereby, the total reaction rate of $\mathrm{R} 1$ was taken from Lee et al. [68], which is 155 in very good agreement with the experimental values of Vinkier and Debruyn 
[69]. The branching ratios of $\mathrm{R} 1$ were updated to the values of Blitz et al. [70] as suggested by Smith et al. [71]. The reaction rates of R2 were taken from the recent quantum chemical study of Goldsmith et al. [72].

The study on the low pressure $\mathrm{CH}_{4}$ flames [8] showed a strong influence of $\mathrm{HCO}$ dissociation due to its weakly bound $\mathrm{H}$ atom, as mentioned before. Therefore, partial decomposition of HCO formed was considered in the mechanism as suggested by Labbe et al. [7]. Additionally, submodels for excited $\mathrm{OH}$ and $\mathrm{CH}$ radicals - required for the ST data - were added as done before in prior work $[15,73,74]$.

The thermodynamic data for heat capacities, enthalpies and entropies where updated to recent values of the Active Thermochemical Tables Thermochemical Network (ATcT TN) [75]. In this regard, we implemented ATcT TN version 1.122b, which was taken from Glarborg et al. [76].

For a first sensitivity analysis with the linTM the uncertainties of the rate coefficients were set globally to $\Delta \lg (k)=0.5$, to identify the most sensitive reactions. For the most sensitive reactions, the rate coefficients and their uncertainties were updated from literature values - mainly from Baulch et al. [9], but also other references [10, 13, 40, 45, 68, 70, 72, 77-90].

For the optimisation of the mechanism the rate coefficients were constrained within their $3 \sigma$ uncertainty range. 89 reactions were optimised with a total of 475 parameters, which are mainly the Arrhenius parameters of the rate coefficients. Parameters were only optimised if one of their sensitivity $S_{r, j}$ for any characteristic point $j$ was at least $5 \%$ of the maximum sensitivity for this specific characteristic point $j$. With this restriction, parameters are only optimised that are relevant to the set of targeted data. The opti- 
mised mechanism and the base values of the optimised parameters including their uncertainties are given as Supplementary Materials. As a benchmark the optimised chemical kinetic model is compared to established conventional models: POLIMI C1-C3 v1412 [91], FFCM 1.0 [71], USC mech 2.0 [2], Aramco 2.0 [92], a recent model by Glarborg et al. [76] and the in-house model DLR-RG [3]. For all chemical kinetic simulations the open-source software Cantera was used [93].

\section{Results and Discussion}

The unweighted average absolute distances $\bar{d}$ between simulation and experiment of the characteristic points for the different experiments and investigated models are summarised in Table 4 . With the model adaptations of the model DLR-RG these average distances of the base model are moderately reduced. Hence, the performance of the base model is similar to the recent models, which are shown in Table 4.

With the optimisation within the parameter uncertainties it is possible to significantly increase the model's capability to reproduce the all types of experimental data. For that matter, the overall average distance of all targeted points could be reduced by about a factor of two compared to the other models from literature. And, the results of the optimised model DLR SynNG agree considerably better with all investigated experiment types compared to the other models.

\subsection{Laminar Burning Velocities}

The simulation results of the laminar flame speeds by the optimised model are in excellent agreement with the experimental burning velocities. Exam- 
Table 4: List of average absolute distances $\bar{d}$ of the characteristic points between experiments and simulation results with the different chemical kinetic models.

\begin{tabular}{lcccccccc}
\hline Model & Species & $\begin{array}{c}\text { Reactions }^{\mathrm{a}} \\
n=\end{array}$ & $\begin{array}{c}\bar{d}_{\mathrm{ST}} \\
2243\end{array}$ & $\begin{array}{c}\bar{d}_{\mathrm{JSR}} \\
405\end{array}$ & $\begin{array}{c}\bar{d}_{\mathrm{FR}} \\
221\end{array}$ & $\begin{array}{c}\bar{d}_{\mathrm{BF}} \\
26\end{array}$ & $\begin{array}{c}\bar{d}_{\mathrm{FS}} \\
116\end{array}$ & $\begin{array}{c}\bar{d}_{\text {overall }} \\
3011\end{array}$ \\
\hline POLIMI v1412 & 107 & 2642 & 0.308 & 0.066 & 0.274 & 0.313 & 0.055 & 0.264 \\
FFCM 1.0 & 38 & 291 & 0.263 & 0.062 & 0.576 & 0.171 & 0.043 & 0.250 \\
USC 2.0 & 111 & 784 & 0.221 & 0.097 & 0.374 & 0.144 & 0.047 & 0.209 \\
Aramco 2.0 & 493 & 2716 & 0.222 & 0.045 & 0.262 & 0.190 & 0.044 & 0.194 \\
Glarborg 2018 & 151 & 1393 & 0.226 & 0.050 & 0.190 & 0.121 & 0.039 & 0.192 \\
\hline DLR-RG & 65 & 395 & 0.267 & 0.162 & 0.378 & 0.598 & 0.044 & 0.256 \\
Base model & 83 & 747 & 0.181 & 0.087 & 0.353 & 0.126 & 0.050 & 0.176 \\
DLR-SynNG & 83 & 747 & 0.107 & 0.031 & 0.107 & 0.063 & 0.035 & 0.094 \\
(optimised, this work) & & & & & & & & \\
\hline
\end{tabular}

${ }^{\text {a }}$ As counted by Cantera [93]

ples of these comparisons are given in Figures 1-4. Figure 1 shows that the optimised model can predict pure hydrogen and syngas mixtures burning velocities as well as the conventional models. The burning velocities are in very good agreement with the experimental values from the heat flux burner in Figure 1 (b) and (c) and slightly underpredict the burning velocities of the bomb measurements in Figure 1 (a). The reason for the deviation between numerical and experimental results of the bomb experiments can be related to the higher experimental uncertainties of this experiment. These uncertainties are also reflected in the lower weighting for these experimental targets in this optimisation, as mentioned before. Further comparisons are detailed in the Supplementary Materials.

The optimised model also agrees well with measured laminar flame speeds for pure methane for a wide pressure range as shown in Fig. 2. Due to the implementation of the partial dissociation of the weakly bound HCO radical in the chemical kinetic model, the simulated low pressure flame speeds are 

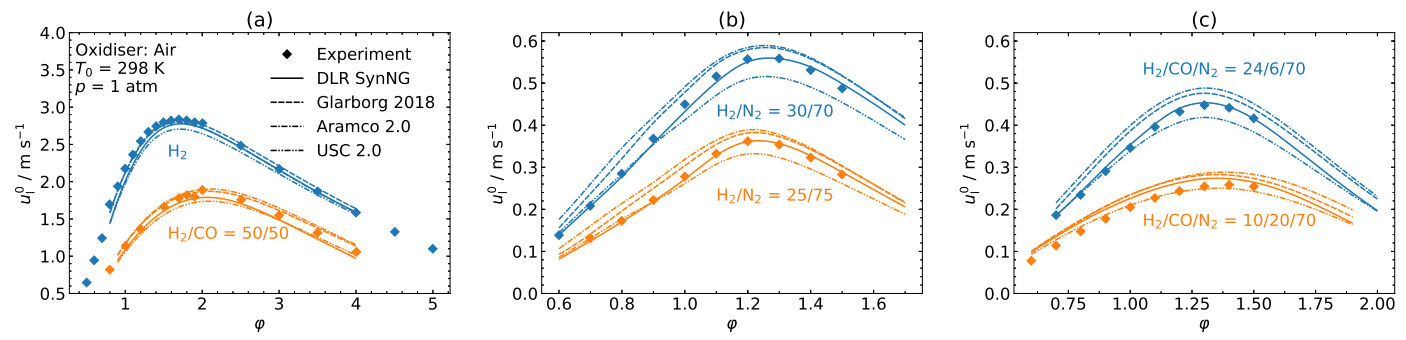

Figure 1: Simulation results of laminar flames speeds of $\mathrm{H}_{2}, \mathrm{CO}$ and their mixtures compared to experimental data from Krejci et al. [48] (a) and Voss et al. [50] (b) and (c)

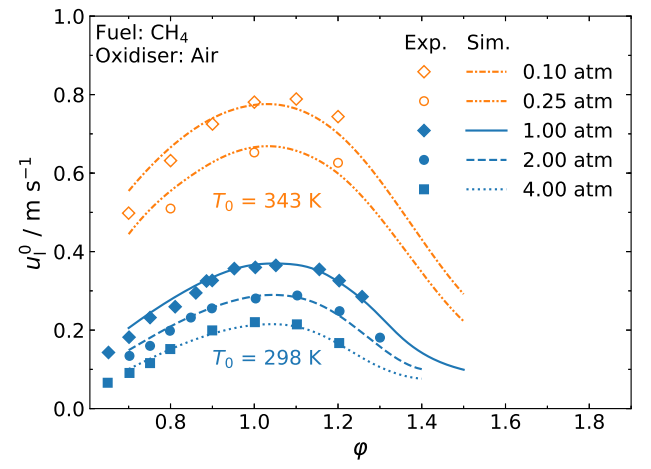

Figure 2: Simulation results of laminar flame speed simulations of methane by the optimised chemical kinetic model compared to experiments from Burrell [8] for sub atmospheric and from Park et al. [58] for atmospheric and elevated pressure

in good agreement with the experimental results [8]. The described pressure range in Fig. 2 is relevant for decentralised power generation from natural gas or biogenic gas mixtures at slightly elevated pressure in micro gas turbine combustion or at subatmospheric pressure e.g. for the inverted Brayton cycle [94].

All compared models agree well with pure syngas mixtures and pure methane burning velocities. Contrary, as shown in Figure 3 none of the con- 


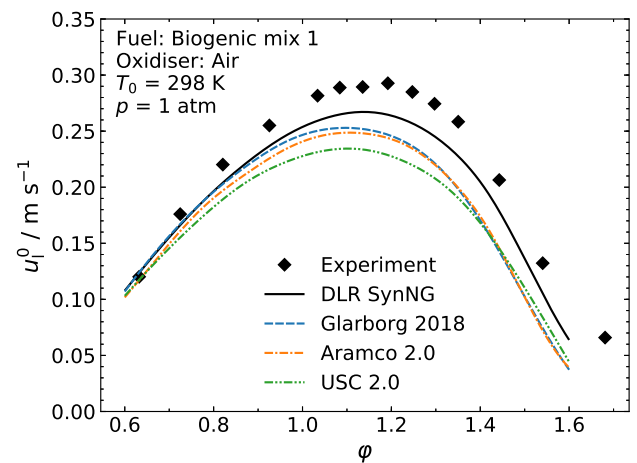

Figure 3: Simulation results of laminar flames speeds of biogenic mix I $\left(\mathrm{H}_{2} / \mathrm{CO} / \mathrm{CH}_{4} / \mathrm{CO}_{2} / \mathrm{N}_{2}=12 / 19 / 5.8 / 13.2 / 50\right)$ compared to experimental data from Yan et al. [6]

ventional models is capable to reproduce the laminar burning velocities of the mixed syngas methane fuel or biogenic fuel mix, respectively. Thus, only the optimised model is able to consistently reproduce the laminar burning velocities of syngas and methane as well as their mixtures.

For the simulation of combustion processes with natural gas, accurate modelling of the kinetics of the $\mathrm{C}_{2}$ species is required. In this regard, also the burning velocities for the $\mathrm{C}_{2}$ species are consistently reproduced by the optimised model (Figure 4). Thereby, Figure 4 (a) illustrates a significant increase in accuracy predicting the experimental data for the ethane combustion from Park et al. [63].

\subsection{Ignition Delay Times}

The average distances of the targeted shock tube data $\bar{d}_{\mathrm{ST}}$ is decreased by around a factor of two compared to the conventional models. The average distances by the optimised model are considerably small compared to general 

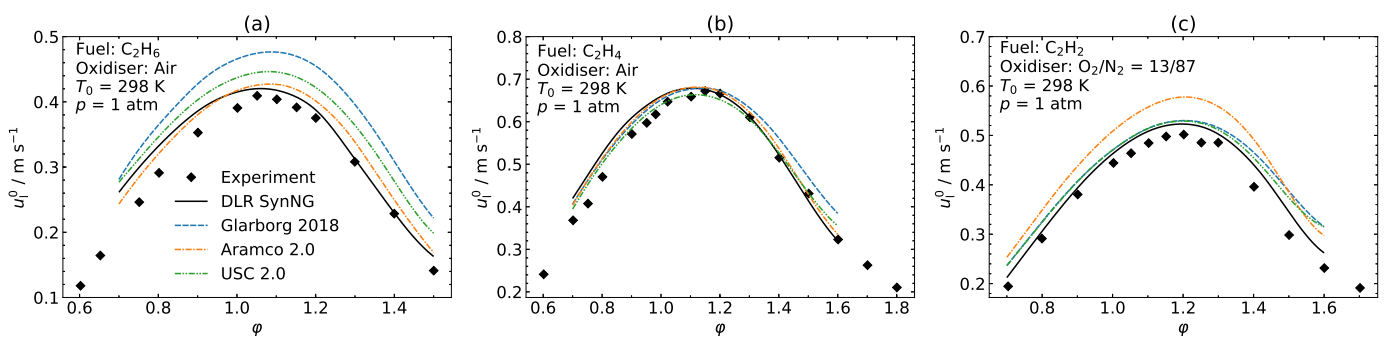

Figure 4: Simulation results of laminar flame speed simulations of $\mathrm{C}_{2}$ fuels compared to experiments from Park et al. [63]

assumption of approximately $15 \%$ standard deviation of the statistical error of shock tube measurements - mainly caused by the temperature estimation of the initial temperature behind reflected shock waves [66]. But in this study, mainly shock tube experiments with known temporal pressure profiles have been implemented into the optimisation process, for which studies have indicated a significantly smaller statistical error [65], which is also confirmed by this work.

Measured ignition delay times are well and consistently reproduced for a large pressure range for all investigated fuels. This is exemplary shown for syngas and methane and their mixtures in Fig. 5 and for ethane, ethylene and acetylene in Fig. 6.

Figure 5 (a) illustrates that reproducibility of the ignition delay times of the syngas mixture at high pressures is significantly increased by the optimised model compared to the conventional models. Similar observations of increasing reproducibility can be demonstrated for the ignition delay times of the $\mathrm{C}_{2}$ species in Fig. 6. The whole model performance on the ignition delay times is shown in the Supplementary Materials. 

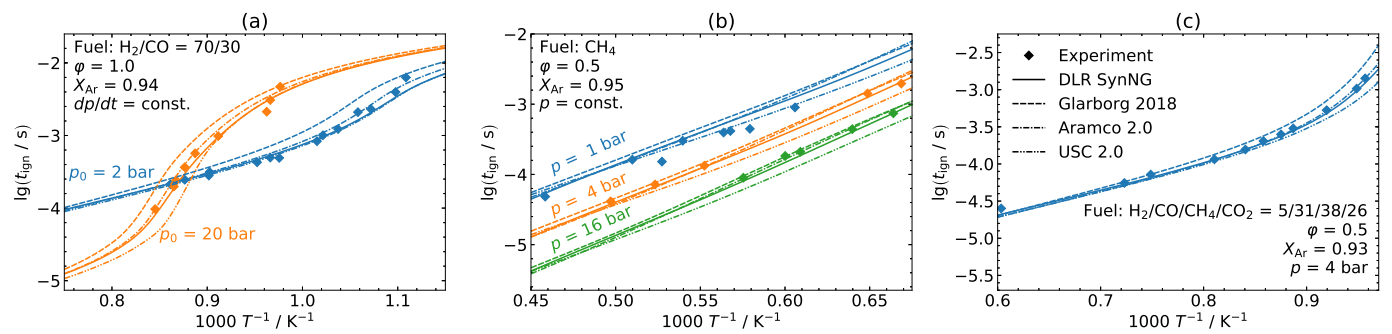

Figure 5: Simulation results of ignition delay times of syngas, $\mathrm{CH}_{4}$ and their mixture compared to experimental data from Thi et al. [22] (a) and Herzler et al. [31] (b) and (c)
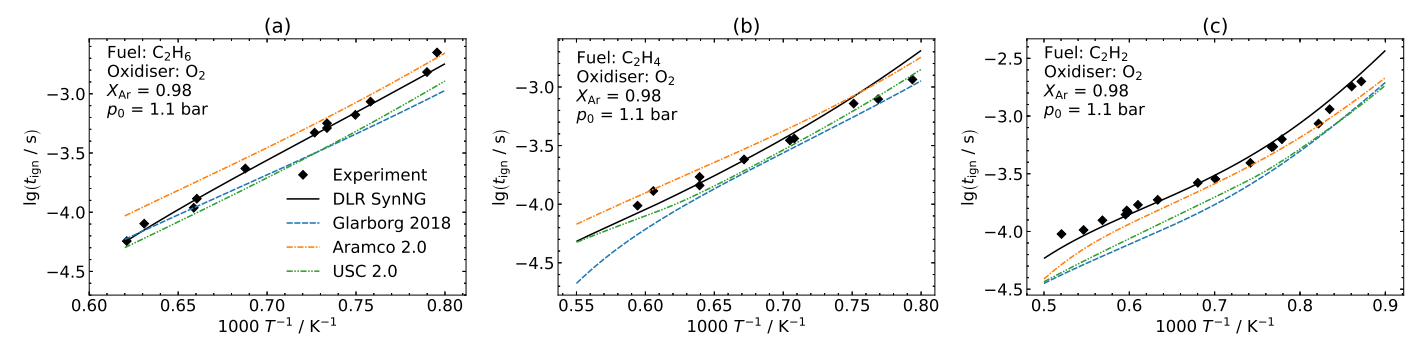

Figure 6: Simulation results of ignition delay times of syngas, $\mathrm{CH}_{4}$ and their mixture compared to experimental data from Vries et al. [30] (a), Petersen et al. [29] (b) and Rickard et al. [27] (c) 

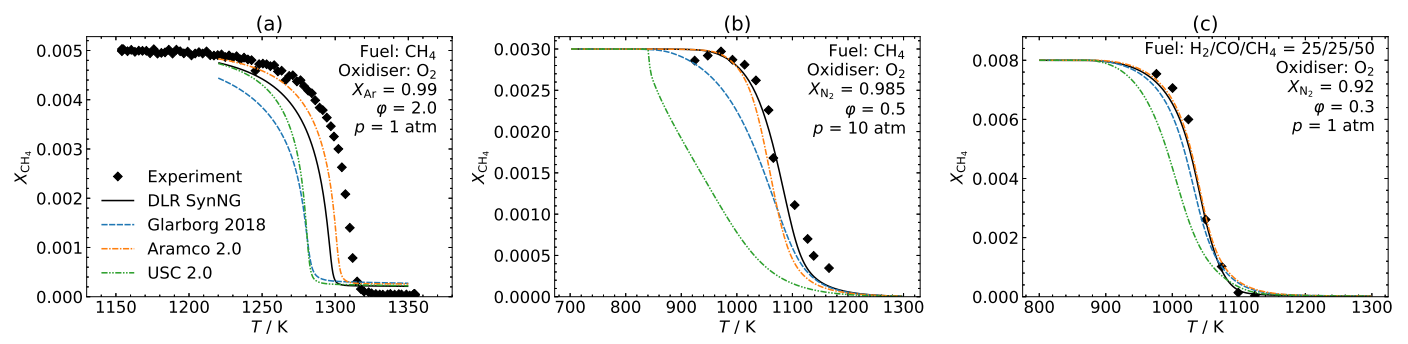

Figure 7: Simulation results of $\mathrm{CH}_{4}$ profiles from the oxidation of $\mathrm{CH}_{4}$ and its mixture with syngas compared to experimental FR data from Oßwald et al. [37] (a) and JSR data from Dagaut et al. [5] (b) and (c)

\subsection{Species Profiles}

Figure 7 shows that the low temperature oxidations of $\mathrm{CH}_{4}$ in the $\mathrm{FR}$ (a) and the JSR (b) and (c) are in good agreement with the optimised model. Contrary, the model USC 2.0 overestimate the consumption of $\mathrm{CH}_{4}$ at lower temperatures for both independent experiment types. Firstly, the optimisation with the linTM is successfully applied to data from the JSR, which is demonstrated further by the exemplary results of the intermediate $\mathrm{C}_{2} \mathrm{H}_{4}$ from the combustion of $\mathrm{CH}_{4}$ and mixtures with syngas (Fig. 8). To wit, the simulated $\mathrm{C}_{2} \mathrm{H}_{4}$ profiles of the optimised model are in very good agreement for atmospheric pressure (a) and (c) and at elevated pressure (b). Thereby, the maximum concentration as well as the time scales of production and consumption of $\mathrm{C}_{2} \mathrm{H}_{4}$ are accurately reproduced.

Figures 9 and 10 show that the oxidation of $\mathrm{C}_{2} \mathrm{H}_{4}$ and $\mathrm{C}_{2} \mathrm{H}_{2}$ are also well reproduced with the optimised model. Contrary, all conventional model overestimate the consumption of $\mathrm{C}_{2} \mathrm{H}_{4}$ in the FR and $\mathrm{C}_{2} \mathrm{H}_{2}$ in the JSR. Also, the time scales and the maximum concentration of the intermediate $\mathrm{CH}_{4}$ are in 

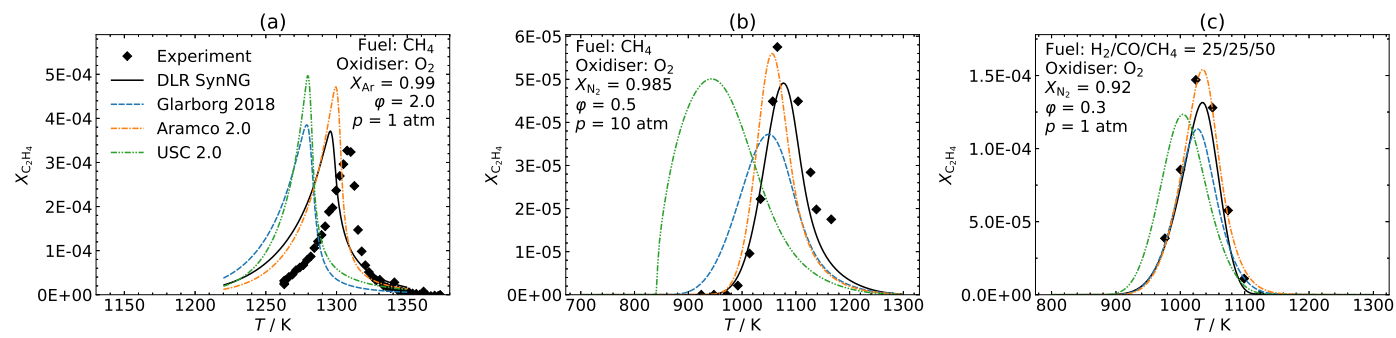

Figure 8: Simulation results of $\mathrm{C}_{2} \mathrm{H}_{4}$ profiles from the oxidation of $\mathrm{CH}_{4}$ and its mixture with syngas compared to experimental FR data from Oßwald et al. [37] (a) and JSR data from Dagaut et al. [5] (b) and (c)

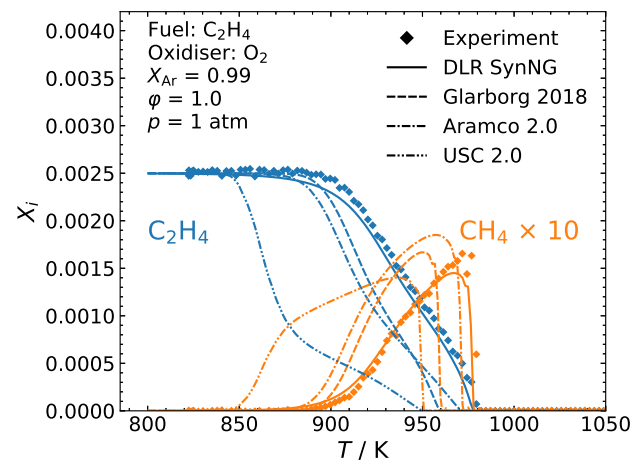

Figure 9: Simulation results of $\mathrm{C}_{2} \mathrm{H}_{4}$ and $\mathrm{CH}_{4}$ profiles from the oxidation of $\mathrm{C}_{2} \mathrm{H}_{4}$ compared to experimental FR data from Oßwald et al. [37]

very good agreement with the optimised model. Especially the reproducibility of the experimental data of $\mathrm{CH}_{4}$ in the JSR can be significantly increased compared to the conventional models.

Also the experimental and numerical species profiles of the burner stabilised flame (BF) are in good agreement (Fig.11). All models are in good agreement with the peak concentration of singlet methylene ${ }^{1} \mathrm{CH}_{2}$ for the stoichiometric case, with the exception of the model USC 2.0. In contrast, 


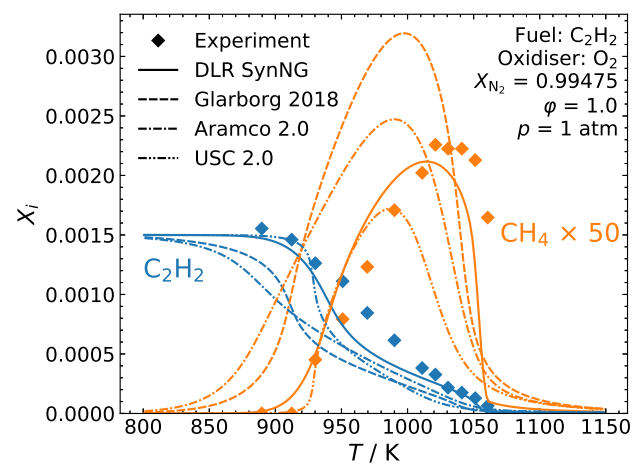

Figure 10: Simulation results of $\mathrm{C}_{2} \mathrm{H}_{2}$ and $\mathrm{CH}_{4}$ profiles from the oxidation of $\mathrm{C}_{2} \mathrm{H}_{2}$ compared to experimental JSR data from Tan et al. [45]

only the optimised model is able to reproduce the experimental data at rich conditions.

In general the capability of optimised model to reproduce the species profiles is one of its major advantages compared to the conventional models considered in this study. Especially the formation of intermediate hydrocarbons is essential for the formation of prompt NO. Thereby, the optimised model with an addition of a NO submodel could have an eminent impact on the accurate simulation of oxidation processes in combustion machinery, and therefore, being crucial for the design of low pollutant applications. Additionally, a significant increase in reproducibility was observed for the toxic intermediate $\mathrm{CH}_{2} \mathrm{O}$ (see Supplementary Materials), which is also important for the design of low pollutant combustion, particularly when oxygenated hydrocarbon fuels are burnt [95]. 


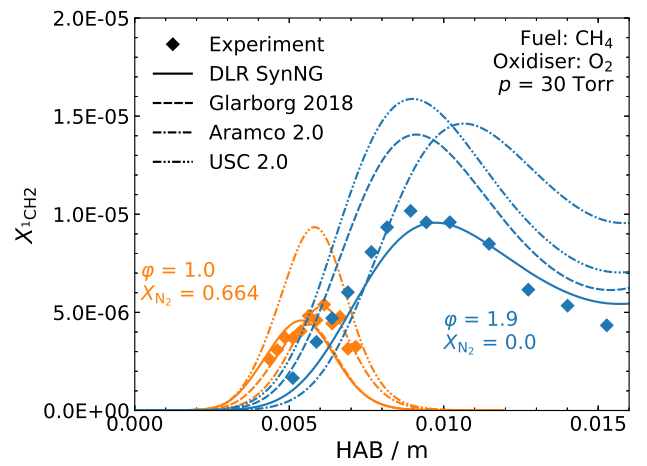

Figure 11: Simulation results of ${ }^{1} \mathrm{CH}_{2}$ profiles from the oxidation of $\mathrm{CH}_{4}$ compared to experimental BF data from Fomin et al. [47]

\subsection{Optimised Chemical Kinetic Model}

The global sensitivity coefficients $S_{r}$ as defined in Eq. (3) for the reaction rates of the base model $k_{0}$ and the optimised model $k_{\mathrm{opt}}$ are given in Fig. 12. For the linTM these sensitivities are normalised with their maximum uncertainty. The trend for most $S_{r}$ of the reactions does not change significantly, demonstrating the robustness of this definition of the global sensitivity. There are also exceptions to that, which will be discussed later in this section.

A profound uncertainty estimation of the model parameters - or rate coefficients, respectively - is challenging and almost impractical from these kinds of optimisation approaches. The main reasons are: (a) Due to the high number of model parameters in chemical kinetic models for the investigated combustion processes, systematic errors - e.g. not yet discovered important pathways or significant under- or overestimations of rate coefficients - cannot be fully excluded; (b) also systematic errors from experiments cannot be fully 

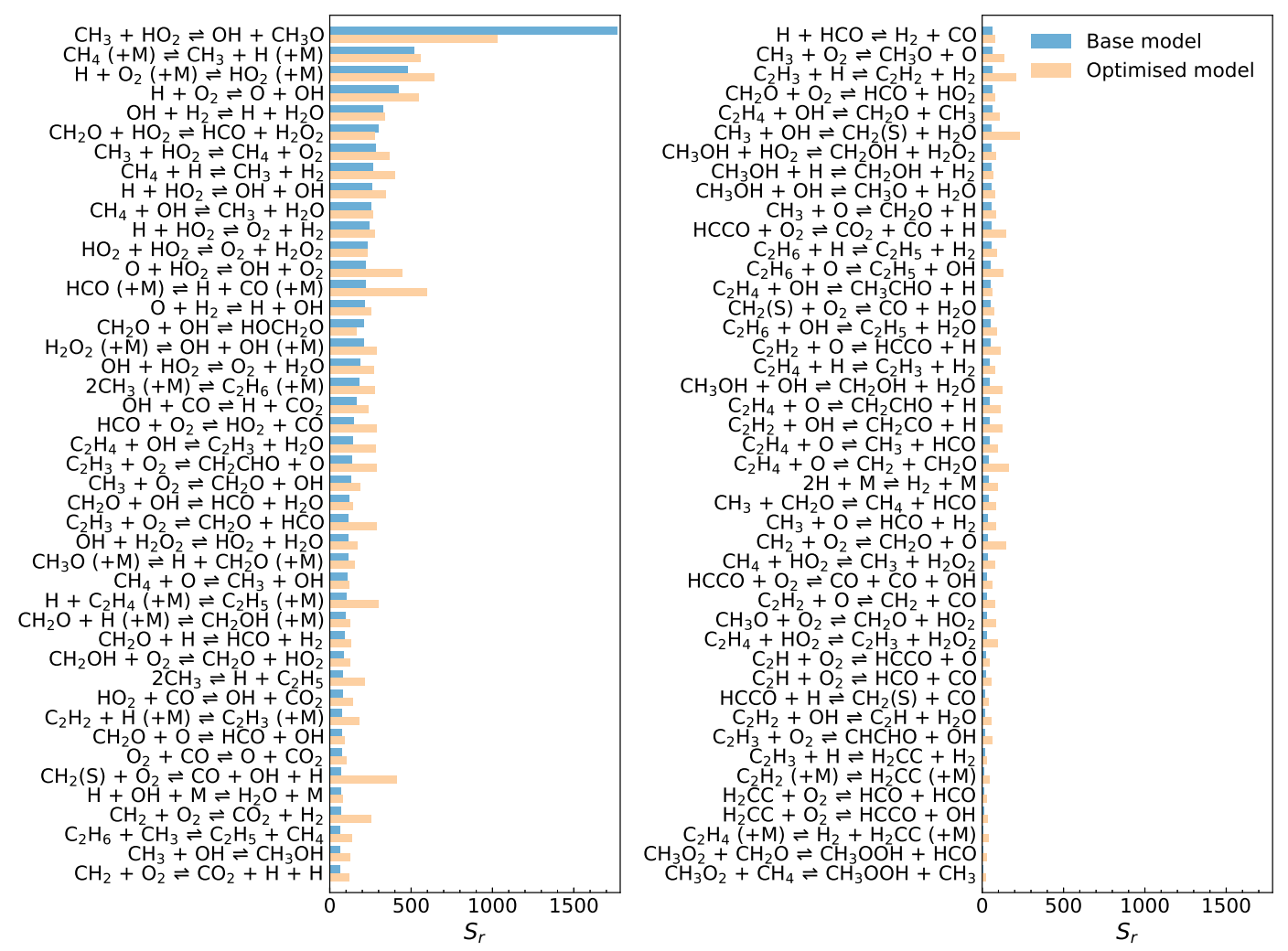

Figure 12: Results of the global sensitivity analysis of the optimised reactions before and after the optimisation 
Table 5: Reaction rate coefficients of the 20 most sensitive reactions before and after optimisation

\begin{tabular}{|c|c|c|c|c|c|c|c|c|}
\hline \multirow[b]{2}{*}{ Reaction } & \multicolumn{5}{|c|}{ Base model } & \multicolumn{3}{|c|}{ Optimised model } \\
\hline & $A$ & $b$ & $E_{\mathrm{A}}$ & $\Delta \lg (k)_{\max }$ & Ref. & $A$ & $b$ & $E_{\mathrm{A}}$ \\
\hline $\mathrm{CH}_{3}+\mathrm{HO}_{2} \rightleftharpoons \mathrm{OH}+\mathrm{CH}_{3} \mathrm{O}$ & $1.81 \mathrm{e}+13$ & 0.00 & 0.0 & 1.00 & {$[9]$} & $1.37 \mathrm{e}+18$ & -1.81 & -2225.8 \\
\hline $\mathrm{CH}_{4}(+\mathrm{M}) \rightleftharpoons \mathrm{CH}_{3}+\mathrm{H}(+\mathrm{M})$ & $6.41 \mathrm{e}+17$ & -0.00 & 89812.0 & 0.50 & {$[86]$} & $6.76 \mathrm{e}+06$ & 3.35 & 88926.4 \\
\hline $\mathrm{H}+\mathrm{O}_{2}(+\mathrm{M}) \rightleftharpoons \mathrm{HO}_{2}(+\mathrm{M})$ & $1.74 \mathrm{e}+19$ & -1.23 & 0.0 & 0.20 & {$[78]$} & $1.46 \mathrm{e}+19$ & -1.22 & 0.0 \\
\hline $\mathrm{H}+\mathrm{O}_{2} \rightleftharpoons \mathrm{O}+\mathrm{OH}$ & $1.04 \mathrm{e}+14$ & 0.00 & 15286.0 & 0.07 & {$[77]$} & $5.01 \mathrm{e}+12$ & 0.33 & 13622.8 \\
\hline $\mathrm{OH}+\mathrm{H}_{2} \rightleftharpoons \mathrm{H}+\mathrm{H}_{2} \mathrm{O}$ & $2.16 \mathrm{e}+08$ & 1.52 & 3430.0 & 0.30 & {$[9]$} & $9.14 \mathrm{e}+06$ & 1.91 & 2995.7 \\
\hline $\mathrm{CH}_{2} \mathrm{O}+\mathrm{HO}_{2} \rightleftharpoons \mathrm{HCO}+\mathrm{H}_{2} \mathrm{O}_{2}$ & $1.00 \mathrm{e}+12$ & 0.00 & 8000.0 & 0.50 & {$[3]$} & $7.28 \mathrm{e}-09$ & 6.03 & -21.3 \\
\hline $\mathrm{CH}_{3}+\mathrm{HO}_{2} \rightleftharpoons \mathrm{CH}_{4}+\mathrm{O}_{2}$ & $1.16 \mathrm{e}+05$ & 2.23 & -3022.0 & 0.50 & {$[83]$} & $1.11 \mathrm{e}+19$ & -1.97 & 2298.5 \\
\hline $\mathrm{CH}_{4}+\mathrm{H} \rightleftharpoons \mathrm{CH}_{3}+\mathrm{H}_{2}$ & $6.14 \mathrm{e}+05$ & 2.50 & 9581.9 & 0.40 & [9] & $3.50 \mathrm{e}+02$ & 3.48 & 7486.9 \\
\hline $\mathrm{H}+\mathrm{HO}_{2} \rightleftharpoons \mathrm{OH}+\mathrm{OH}$ & $5.79 \mathrm{e}+13$ & 0.00 & 170.9 & 0.20 & {$[13]$} & $7.30 \mathrm{e}+01$ & 3.76 & -3301.9 \\
\hline $\mathrm{CH}_{4}+\mathrm{OH} \rightleftharpoons \mathrm{CH}_{3}+\mathrm{H}_{2} \mathrm{O}$ & $1.37 \mathrm{e}+06$ & 2.18 & 2680.9 & 0.30 & [9] & $3.81 \mathrm{e}+13$ & -0.09 & 4956.9 \\
\hline $\mathrm{H}+\mathrm{HO}_{2} \rightleftharpoons \mathrm{O}_{2}+\mathrm{H}_{2}$ & $2.12 \mathrm{e}+06$ & 2.11 & -1623.8 & 0.30 & {$[13]$} & $1.65 \mathrm{e}+02$ & 3.16 & -6376.0 \\
\hline $\mathrm{HO}_{2}+\mathrm{HO}_{2} \rightleftharpoons \mathrm{O}_{2}+\mathrm{H}_{2} \mathrm{O}_{2}$ & $4.22 \mathrm{e}+14$ & 0.00 & 11974.8 & 0.40 & {$[9]$} & $1.16 \mathrm{e}+21$ & -1.94 & 14798.4 \\
\hline $\mathrm{O}+\mathrm{HO}_{2} \rightleftharpoons \mathrm{OH}+\mathrm{O}_{2}$ & $1.63 \mathrm{e}+13$ & 0.00 & -444.8 & 0.50 & {$[9]$} & $1.71 \mathrm{e}+06$ & 2.47 & -1692.7 \\
\hline $\mathrm{HCO}(+\mathrm{M}) \rightleftharpoons \mathrm{H}+\mathrm{CO}(+\mathrm{M})$ & $4.94 \mathrm{e}+10$ & 0.96 & 14631.8 & 0.30 & {$[13]$} & $1.24 \mathrm{e}+43$ & -8.37 & 33089.7 \\
\hline $\mathrm{O}+\mathrm{H}_{2} \rightleftharpoons \mathrm{H}+\mathrm{OH}$ & $3.83 \mathrm{e}+12$ & 0.00 & 7943.5 & 0.20 & [9] & $1.94 \mathrm{e}+15$ & -0.80 & 8746.1 \\
\hline $\mathrm{CH}_{2} \mathrm{O}+\mathrm{OH} \rightleftharpoons \mathrm{HOCH}_{2} \mathrm{O}$ & $4.50 \mathrm{e}+15$ & -1.10 & 0.0 & 0.50 & {$[3]$} & $9.77 \mathrm{e}+14$ & -1.13 & 0.0 \\
\hline $\mathrm{H}_{2} \mathrm{O}_{2}(+\mathrm{M}) \rightleftharpoons \mathrm{OH}+\mathrm{OH}(+\mathrm{M})$ & $1.20 \mathrm{e}+17$ & 0.00 & 45476.6 & 0.20 & {$[9]$} & $1.22 \mathrm{e}-12$ & 8.59 & 31740.3 \\
\hline $\mathrm{OH}+\mathrm{HO}_{2} \rightleftharpoons \mathrm{O}_{2}+\mathrm{H}_{2} \mathrm{O}$ & $9.58 \mathrm{e}+11$ & 0.42 & -948.1 & 0.20 & {$[13]$} & $4.66 \mathrm{e}+09$ & 1.06 & -2811.4 \\
\hline $2 \mathrm{CH}_{3}(+\mathrm{M}) \rightleftharpoons \mathrm{C}_{2} \mathrm{H}_{6}(+\mathrm{M})$ & $1.27 \mathrm{e}+41$ & -7.00 & 2760.4 & 0.30 & {$[9]$} & $3.13 \mathrm{e}+47$ & -8.68 & 6435.5 \\
\hline $\mathrm{OH}+\mathrm{CO} \rightleftharpoons \mathrm{H}+\mathrm{CO}_{2}$ & $2.23 \mathrm{e}+05$ & 1.90 & -1160.0 & 0.20 & {$[36]$} & $1.90 \mathrm{e}+05$ & 1.91 & -1211.7 \\
\hline
\end{tabular}

Units: $A$ : cm, mol, s; $E_{\mathrm{A}}$ : $\mathrm{cal} \mathrm{mol}^{-1}$

${ }^{\mathrm{a}}$ Low pressure values of fall-off reaction 
neglected. Consequently, uncertainty quantification results can be highly influenced by systematic errors. Therefore, resulting rate coefficients and their uncertainties estimations from these optimisation approaches should not be seen as physically granted parameter boundaries and can otherwise be misleading for chemical kinetic modelling. Hence, implementing these results into other models needs to be done thoroughly with diligent validation. Nevertheless, valuable information from these optimisation approaches can still be gained for sensitive reactions, to give leads towards further investigations for certain reactions. For this purpose, we define a local solution space $\lambda_{\Delta}$ that is defined by the solutions for which the objective function satisfies:

$$
\lambda_{\Delta}=F \leq \sum_{j=1}^{D}\left(w_{j} d_{\mathrm{opt}, j}\right)^{2}(1+\Delta)^{2} .
$$

In this equation $d_{\mathrm{opt}, j}$ are the distances for the optimised model and $\Delta$ is an approximated relative increase of the standard deviation of the distances. With the simplified linearity approximation of the linTM, solutions of the objective function can be estimated. This estimation is shown in Fig. 13 (a) and (b) for an exemplary reaction with its model parameters $\Delta \lg \left(k\left(T_{1}\right)\right)$, $\Delta \lg \left(k\left(T_{1}\right)\right)$ and $\Delta E_{\mathrm{A}}$ (which define the reaction rate coefficient $k(T)$ and are also shown in Fig. 14). Combinations of input parameters that fulfil Eq. (4) can be found analytically, which are also plotted in Fig. 13 for $\lambda_{0.2}$. In the solution space of the three model parameters of the reaction rate coefficient in Fig. 13 (c), the solution space $\lambda_{\Delta}$ becomes an angled ellipsoid. The parameter combinations fulfilling $\lambda_{0.2}$ from Fig. 13 (c) can then be projected to the corresponding boundaries of the optimised rate coefficient $k_{\text {opt }}(T)$ in Fig. 14. 

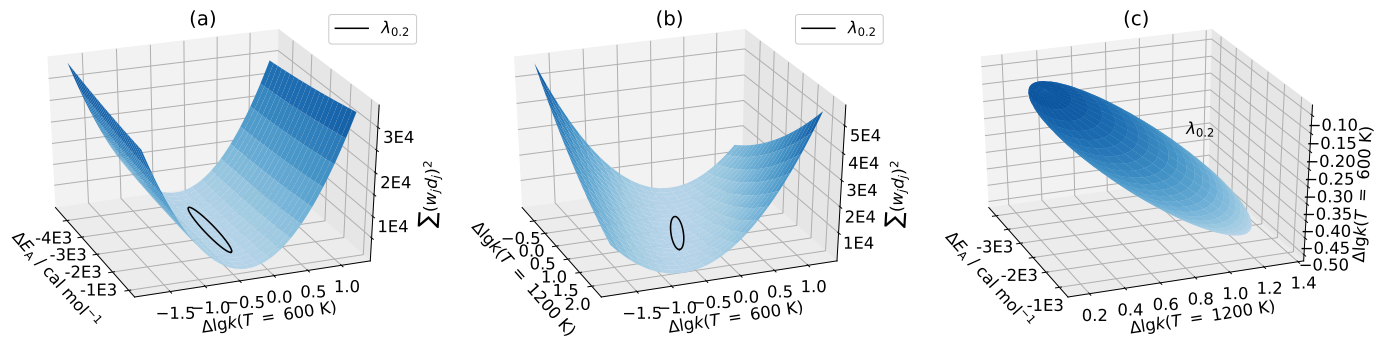

Figure 13: Estimation of the objective function with the deviation of the model parameters of reaction $\mathrm{CH}_{3}+\mathrm{HO}_{2} \rightleftharpoons \mathrm{CH}_{3} \mathrm{O}+\mathrm{OH}$ (a) and (b) and the corresponding local solution space $\lambda_{\Delta}$ formed by the model parameter (c)

Figures 14 and 15 show the results of the local solution space investigations of the reactions:

$$
\begin{aligned}
\mathrm{CH}_{3}+\mathrm{HO}_{2} & \rightleftharpoons \mathrm{CH}_{3} \mathrm{O}+\mathrm{OH}, \\
& \rightleftharpoons \mathrm{CH}_{4}+\mathrm{O}_{2},
\end{aligned}
$$

for which R3a is the most sensitive reaction of this optimisation problem. Figure 14 illustrates that the local solution space $\lambda_{\Delta}$ of $k(T)$ of R3a becomes significantly small around temperatures of about $1000 \mathrm{~K}$. In this temperature range, the optimised $k_{\mathrm{opt}}(T)$ is in excellent agreement with and supported by the experimental estimation of Scire et al. [96] and the review value of Baulch et al. [9] - here the base rate coefficient $k_{0}$. The optimised value of the $E_{\mathrm{A}}$ of R3a is $-2.225 \mathrm{cal} / \mathrm{mol}$. Negative temperature dependencies can be found for various reactions and are implemented in any modern detailed chemical kinetic model. Reasons are for instance temperature dependencies of activation energies, which not necessarily have to be constant. Also more complex reaction phenomena cannot be fully displayed by the highly simplified theory behind the semi-empirical Arrhenius equation, for which the 


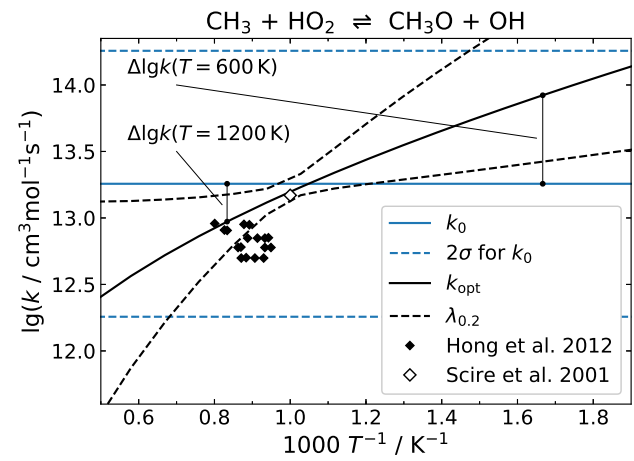

Figure 14: Optimised rate coefficient of reaction R3a with the base model $k_{0}$ from Baulch et al. [9] and experimental results from Scire et al. [96] and Hong et al. [97]

Arrhenius parameter become pure fitting parameters (e.g. [72]). A negative $E_{\mathrm{A}}$ for reaction R3a was also reported by quantum chemical calculations [83]. Furthermore, with the negative $E_{\mathrm{A}}$, the model even agrees well with the the upper values of highly scattered experimental estimation of R3a by shock tube experiments from Hong et al. [97], supporting the optimised result.

Figure 15 illustrates that channel R3b agrees very well with experimental results from Hong et al. [97] and Scire et al. [96] and quantum chemical modelling results from Jasper et al. [83] (here $k_{0}$ ) around the temperature range of 1000-1200 K. For higher temperatures the values of the optimised value $k_{\mathrm{opt}}$ and the base model value $k_{0}$ from Jasper et al. [83] show different trends and diverge. Srinivasan et al. [98] studied the reverse reaction of R3b experimentally. The corresponding values from reversing their results are also shown in Fig. 15 and their highly scattered data agree with both rate coefficients $k_{\mathrm{opt}}$ and $k_{0}$. Thus, for final conclusions on the rate coefficient value of R3b at higher temperatures more investigations are required. 


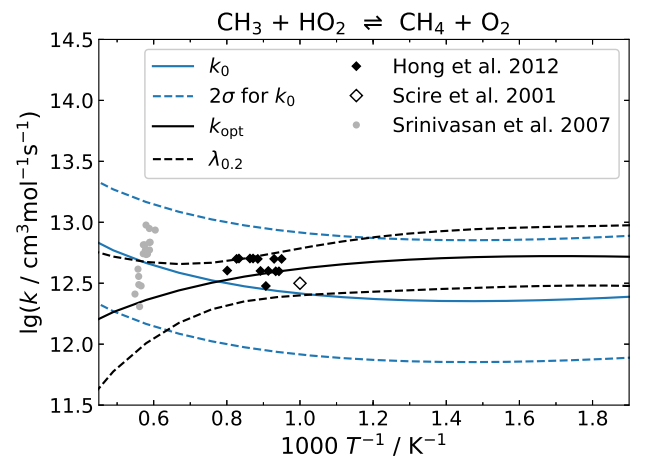

Figure 15: Optimised rate coefficient of reaction R3b with the base model $k_{0}$ from Jasper et al. [83] and experimental results from Scire et al. [96], Srinivasan et al. [98] and Hong et al. [97]

Another sensitive reaction that has been studied intensively by experiments is:

$$
\mathrm{CH}_{4}(+\mathrm{M}) \rightleftharpoons \mathrm{CH}_{3}+\mathrm{H}(+\mathrm{M}),
$$

for which the optimisation results are shown in Fig. 16. Even though the experimental values of Davidson et al. [99] were not directly targeted by the optimisation, the optimised rate coefficient $k_{\mathrm{opt}}$ is in outstanding good agreement with the experimental data. Also the trend of $k_{\text {opt }}$ agrees well with the experimental data of Wang et al. [86], which were experimentally determined in a shock tube study at lower temperature. Therefore, deviations can be associated with higher uncertainties of shock tube results regarding low temperatures [66].

In general, there is a very good agreement of the presented, sensitive rate coefficients with the independent experimental determinations. This indicates a potentially low impact of a systematic error on the optimisation 


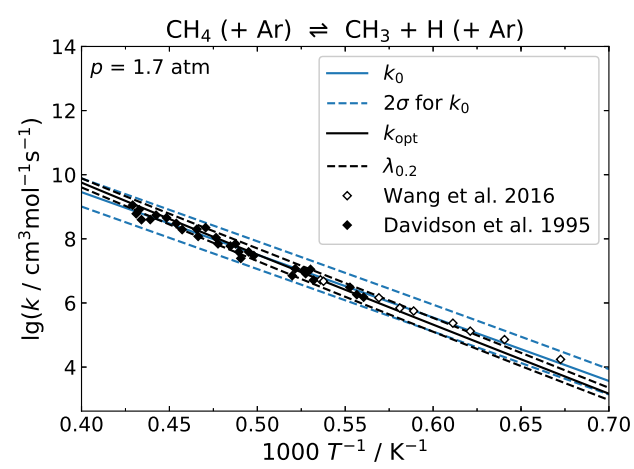

Figure 16: Optimised rate coefficient of reaction $\mathrm{R} 4$ with the base model $k_{0}$ from Wang et al. [86] and experimental results from Wang et al. [86] and Davidson et al. [99]

results of this work.

A reaction that significantly increased its global sensitivity coefficient $S_{r}$ after the optimisation is the reaction of singlet methylene with molecular oxygen:

$$
{ }^{1} \mathrm{CH}_{2}+\mathrm{O}_{2} \rightleftharpoons \mathrm{CO}+\mathrm{OH}+\mathrm{H} \text {. }
$$

Figure 17 shows that the value $k_{\text {opt }}$ is pushed to the upper boundary of $3 \sigma$ after the optimisation process. Since R5 is a chain branching reaction, the increased value has a high impact on the combustion processes investigated in this study, therefore, leading to the increased $S_{r}$. There have been a few experimental investigations on reaction R5a with contrary results. On the one hand Shaub et al. [100] concluded, that R5a was the main channel for the reaction of ${ }^{1} \mathrm{CH}_{2}$ with $\mathrm{O}_{2}$, which was applied to the direct measurement of the overall rate of the reaction of ${ }^{1} \mathrm{CH}_{2}$ with $\mathrm{O}_{2}$ by Langford et al. [101]. In contrast experiments by Hancock et al. [102] indicated that the main channel for this reaction was the deactivation of singlet methylene to triplet 


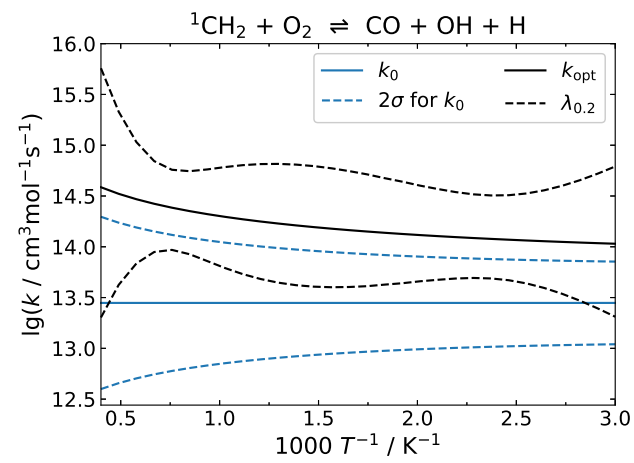

Figure 17: Optimised rate coefficient of reaction R5 with the base model $k_{0}$ from Langford et al. [101]

methylene, for which $\mathrm{O}_{2}$ just acts as a third body:

$$
{ }^{1} \mathrm{CH}_{2}+\mathrm{O}_{2} \rightleftharpoons{ }^{3} \mathrm{CH}_{2}+\mathrm{O}_{2} \text {. }
$$

But also with the indications of Hancock et al. [102] no final conclusion on the reaction of ${ }^{1} \mathrm{CH}_{2}$ with $\mathrm{O}_{2}$ can be drawn.

The incorporation of reaction R5 is consequently inconclusive among recent chemical kinetic models. For instance is the value suggested by Langford et al. [101] is incorporated in the models like GRI 3.0 [1], USC 2.0 [2] or Aramco 2.0 [92], but this reaction is completely left out in the model of Glarborg et al. [76]. The possible importance of reaction R5 in the optimised model underlines the need of further investigations on the rate coefficient of this reaction, e.g., by quantum chemical simulations of the reaction.

\section{Conclusions}

Within this work an optimised chemical kinetic model was established, which can reproduce fundamental experimental data from the oxidation of 
fuel mixtures of $\mathrm{H}_{2}, \mathrm{CO}, \mathrm{CH}_{4}$ and $\mathrm{C}_{2}$ species with high accuracy. The average deviation between experimental and simulated targets can be reduced by a factor of two compared to conventional models. The optimised model can consistently reproduce data from shock tubes, flow reactors, jet stirred reactors and different burner types. Here, the reproduction of low temperature combustion in flow reactors and jet stirred reactors could be significantly improved. Also the laminar flame speeds of mixtures of syngas and methane are reproduced more accurately compared to the conventional models. The combustion model is valid for a wide range of boundary conditions, relevant for applied combustion systems, e.g., for power generation from biogenic gases in decentralised units. Due to the implementation of partial dissociation of the weakly bound HCO radical, the model is also capable to accurately reproduce data at subatmospheric conditions.

Thus, the optimised combustion model is capable of reproducing relevant combustion characteristics for the design of combustion machinery, like the ignition behaviour, the heat release and intermediate species. Whereas ignition behaviour and heat release are important for the reliability (e.g. flashback risk) and the dimensioning of combustion chambers, heat release and intermediates are also important for the prediction of pollutant emissions. Thereby, intermediates can directly be pollutants. Additionally, when adding $\mathrm{NO}_{\mathrm{x}}$ models, heat release is important for the accurate modelling of thermal $\mathrm{NO}_{\mathrm{x}}$ and the accurate modelling of hydrocarbon intermediates is important for the prediction of prompt NO.

Therefore, the chemical kinetic model can be used for the numerical design or adaptation of combustion chambers, e.g., by CFD simulations, to 
guarantee reliable operation of combustion machinery at low pollutant emission levels. In this context the chemical kinetic model can also serve as a base model for the generation of numerically efficient reduced models.

With the analysis of the chemical kinetic model, the reaction of singlet methylene with molecular oxygen was identified as a key reaction in the optimised model. For this reaction further investigations seem to be of high interest, e.g., by quantum chemical modelling approaches. For the further chemical kinetic evaluation of the rate coefficients more experimental data could be collected and implemented into the overall optimisation process. As examples species profiles probed from flat laminar flames and combustion data from rapid compression machines could be implemented. Also, chemical kinetic submodels for $\mathrm{NO}_{\mathrm{x}}$ could be added to the model and included directly in the optimisation process.

On the whole, the optimisation method, utilised in this work, is very general. This optimisation work can be extended and the method can be used on arbitrary reaction schemes for a broad variety of fuels in different fundamental experiments.

\section{Acknowledgments}

The support by the Helmholtz-Gemeinschaft within the project DLR@Uni (Grant No. HA-302) is thankfully acknowledged.

\section{Supplementary Materials}

The optimised chemical kinetic model as well as a full illustration of the model's perfomrance on the targeted experimental data are available as 
Supplementary Materials.

\section{References}

[1] G. P. Smith, D. M. Golden, M. Frenklach, N. W. Moriarty, B. Eiteneer, M. Goldenberg, C. T. Bowman, R. K. Hanson, S. Song, W. C. Gardiner Jr., V. V. Lissianski, Z. Qin, GRI 3.0 mechanism, http: //combustion. berkeley.edu/gri_mech/ (11 2017).

[2] H. Wang, X. You, A. V. Joshi, S. G. Davis, A. Laskin, F. Egolfopoulos, C. K. Law, USC mech version II. high-temperature combustion reaction model of $\mathrm{H} 2 / \mathrm{CO} / \mathrm{C} 1-\mathrm{C} 4$ compounds, http://ignis.usc.edu/ USC_Mech_II.htm (2007).

[3] M. Braun-Unkhoff, N. Slavinskaya, M. Aigner, A detailed and reduced reaction mechanism of biomass-based syngas fuels, Journal of Engineering for Gas Turbines and Power 132 (9) (2010) 091401.

[4] M. Fischer, X. Jiang, An assessment of chemical kinetics for bio-syngas combustion, Fuel 137 (2014) 293-305.

[5] T. Le Cong, P. Dagaut, G. Dayma, Oxidation of natural gas, natural gas/syngas mixtures, and effect of burnt gas recirculation: Experimental and detailed kinetic modeling, Journal of Engineering for Gas Turbines and Power 130 (4) (2008) 041502.

[6] B. Yan, Y. Wu, C. Liu, J. Yu, B. Li, Z. Li, G. Chen, X. Bai, M. Aldén, A. Konnov, Experimental and modeling study of laminar burning ve- 
locity of biomass derived gases/air mixtures, international journal of hydrogen energy 36 (5) (2011) 3769-3777.

[7] N. J. Labbe, R. Sivaramakrishnan, C. F. Goldsmith, Y. Georgievskii, J. A. Miller, S. J. Klippenstein, Weakly bound free radicals in combustion: prompt dissociation of formyl radicals and its effect on laminar flame speeds, The journal of physical chemistry letters 7 (1) (2015) 85-89.

[8] R. R. Burrell, Studies of methane counterflow flames at low pressures, Ph.D. thesis, University of Southern California (2017).

[9] D. L. Baulch, C. T. Bowman, C. J. Cobos, R. Cox, T. Just, J. A. Kerr, M. J. Pilling, D. Stocker, J. Troe, W. Tsang, R. W. Walker, J. Warnatz, Evaluated kinetic data for combustion modeling: Supplement II, J. Phys. Chem. Ref. Data 34 (3) (2005) 757-1397.

[10] S. G. Davis, A. V. Joshi, H. Wang, F. Egolfopoulos, An optimized kinetic model of $\mathrm{H}_{2} / \mathrm{CO}$ combustion, Proceedings of the Combustion Institute 30 (1) (2005) 1283-1292.

[11] X. You, T. Russi, A. Packard, M. Frenklach, Optimization of combustion kinetic models on a feasible set, Proceedings of the Combustion Institute 33 (1) (2011) 509-516.

[12] T. Varga, T. Nagy, C. Olm, I. G. Zsély, R. Pálvölgyi, É. Valkó, G. Vincze, M. Cserháti, H. Curran, T. Turányi, Optimization of a hydrogen combustion mechanism using both direct and indirect mea- 
surements, Proceedings of the Combustion Institute 35 (1) (2015) 589596.

[13] T. Varga, C. Olm, T. Nagy, I. G. Zsély, É. Valkó, R. Pálvölgyi, H. J. Curran, T. Turányi, Development of a joint hydrogen and syngas combustion mechanism based on an optimization approach, International Journal of Chemical Kinetics 48 (8) (2016) 407-422.

[14] H. Lee, A. Mohamad, L. Jiang, A detailed chemical kinetics for the combustion of $\mathrm{H}_{2} / \mathrm{CO} / \mathrm{CH}_{4} / \mathrm{CO}_{2}$ fuel mixtures, Fuel 193 (2017) 294307.

[15] T. Methling, M. Braun-Unkhoff, U. Riedel, A novel linear transformation model for the analysis and optimisation of chemical kinetics, Combustion Theory and Modelling 21 (3) (2017) 503-528.

[16] G. Mittal, S. Gupta, Computational assessment of an approach for implementing crevice containment in rapid compression machines, Fuel 102 (2012) 536-544.

[17] K. P. Grogan, S. S. Goldsborough, M. Ihme, Ignition regimes in rapid compression machines, Combustion and Flame 162 (8) (2015) 30713080.

[18] A. T. Hartlieb, B. Atakan, K. Kohse-Höinghaus, Effects of a sampling quartz nozzle on the flame structure of a fuel-rich low-pressure propene flame, Combustion and flame 121 (4) (2000) 610-624.

[19] N. Hansen, R. Tranter, J. Randazzo, J. Lockhart, A. Kastengren, Investigation of sampling-probe distorted temperature fields with x-ray flu- 
orescence spectroscopy, Proceedings of the Combustion Institute 37 (2) (2019) 1401-1408.

[20] J. Herzler, C. Naumann, P. Griebel, Ignition delay time measurements for the validation of reaction mechanisms for fuels from gasification processes, in: Proceedings of the European Combustion Meeting - 2011, no. 336, European Combustion Meeting, Cardiff, UK, 2011.

[21] D. M. Kalitan, J. D. Mertens, M. W. Crofton, E. L. Petersen, Ignition and oxidation of lean $\mathrm{CO} / \mathrm{H}_{2}$ fuel blends in air, Journal of propulsion and power 23 (6) (2007) 1291-1303.

[22] L. D. Thi, Y. Zhang, Z. Huang, Shock tube study on ignition delay of multi-component syngas mixtures-effect of equivalence ratio, international journal of hydrogen energy 39 (11) (2014) 6034-6043.

[23] J. Herzler, C. Naumann, Ignition delay time measurements for the validation of reaction mechanisms for different alcohols, in: Proceedings of the European Combustion Meeting - 2013, no. P3-8, European Combustion Meeting, Lund, Sweden, 2013.

[24] E. L. Petersen, J. M. Hall, S. D. Smith, J. de Vries, A. R. Amadio, M. W. Crofton, Ignition of lean methane-based fuel blends at gas turbine pressures, Journal of Engineering for Gas Turbines and Power 129 (4) (2007) 937-944.

[25] W. Zeng, H. Ma, Y. Liang, E. Hu, Experimental and modeling study on effects of $\mathrm{N}_{2}$ and $\mathrm{CO}_{2}$ on ignition characteristics of methane/air mixture, Journal of advanced research 6 (2) (2015) 189-201. 
[26] B. Koroglu, O. M. Pryor, J. Lopez, L. Nash, S. S. Vasu, Shock tube ignition delay times and methane time-histories measurements during excess $\mathrm{CO}_{2}$ diluted oxy-methane combustion, Combustion and flame 164 (2016) 152-163.

[27] M. Rickard, J. Hall, E. Petersen, Effect of silane addition on acetylene ignition behind reflected shock waves, Proceedings of the Combustion Institute 30 (2) (2005) 1915-1923.

[28] N. Lokachari, U. Burke, A. Ramalingam, M. Turner, R. Hesse, K. P. Somers, J. Beeckmann, K. A. Heufer, E. L. Petersen, H. J. Curran, New experimental insights into acetylene oxidation through novel ignition delay times, laminar burning velocities and chemical kinetic modelling, Proceedings of the Combustion Institute 37 (1) (2019) 583-591.

[29] E. L. Petersen, J. M. Hall, D. M. Kalitan, M. J. Rickard, Ignition delay time measurements of $\mathrm{c}_{2} \mathrm{~h}_{x}$ fuels and comparison to several detailed kinetics mechanisms, ASME Paper No. GT2004-GT53926.

[30] J. de Vries, J. M. Hall, S. L. Simmons, M. J. Rickard, D. M. Kalitan, E. L. Petersen, Ethane ignition and oxidation behind reflected shock waves, Combustion and flame 150 (1) (2007) 137-150.

[31] J. Herzler, J. Herbst, T. Kick, C. Naumann, M. Braun-Unkhoff, U. Riedel, Alternative fuels based on biomass: An investigation of combustion properties of product gases, Journal of Engineering for Gas Turbines and Power 135 (3) (2013) 031401. 
[32] J. Herzler, C. Naumann, Shock-tube study of the ignition of methane/ethane/hydrogen mixtures with hydrogen contents from $0 \%$ to $100 \%$ at different pressures, Proceedings of the combustion institute 32 (1) (2009) 213-220.

[33] J. Herzler, C. Naumann, Oxy-fuel ignition delay time measurements for validation of reaction mechanisms, Tech. Rep. D1.4.1003, German Aerospace Center, Institute of Combustion Technology (2010).

[34] M. Mueller, T. Kim, R. Yetter, F. Dryer, Flow reactor studies and kinetic modeling of the $\mathrm{H}_{2} / \mathrm{O}_{2}$ reaction, International Journal of Chemical Kinetics 31 (2) (1999) 113-125.

[35] M. A. Mueller, R. Yetter, F. Dryer, Flow reactor studies and kinetic modeling of the $\mathrm{H}_{2} / \mathrm{O}_{2} / \mathrm{NO}_{x}$ and $\mathrm{CO} / \mathrm{H}_{2} \mathrm{O} / \mathrm{O}_{2} / \mathrm{NO}_{x}$ reactions, International Journal of Chemical Kinetics 31 (10) (1999) 705-724.

[36] J. Li, Z. Zhao, A. Kazakov, M. Chaos, F. L. Dryer, J. J. Scire Jr, A comprehensive kinetic mechanism for $\mathrm{CO}, \mathrm{CH}_{2} \mathrm{O}$, and $\mathrm{CH}_{3} \mathrm{OH}$ combustion, International Journal of Chemical Kinetics 39 (3) (2007) 109-136.

[37] P. Oßwald, M. Köhler, An atmospheric pressure high-temperature laminar flow reactor for investigation of combustion and related gas phase reaction systems, Review of Scientific Instruments 86 (10).

[38] H. Hashemi, J. M. Christensen, S. Gersen, H. Levinsky, S. J. Klippenstein, P. Glarborg, High-pressure oxidation of methane, Combustion and Flame 172 (2016) 349-364. 
[39] M. Alzueta, M. Borruey, A. Callejas, A. Millera, R. Bilbao, An experimental and modeling study of the oxidation of acetylene in a flow reactor, Combustion and flame 152 (3) (2008) 377-386.

[40] T. Carriere, P. Westmoreland, A. Kazakov, Y. Stein, F. Dryer, Modeling ethylene combustion from low to high pressure, Proceedings of the Combustion Institute 29 (1) (2002) 1257-1266.

[41] P. Dagaut, F. Lecomte, J. Mieritz, P. Glarborg, Experimental and kinetic modeling study of the effect of $\mathrm{NO}$ and $\mathrm{SO}_{2}$ on the oxidation of $\mathrm{CO}-\mathrm{H}_{2}$ mixtures, International journal of chemical kinetics 35 (11) (2003) 564-575.

[42] U. Burke, W. K. Metcalfe, S. M. Burke, K. A. Heufer, P. Dagaut, H. J. Curran, A detailed chemical kinetic modeling, ignition delay time and jet-stirred reactor study of methanol oxidation, Combustion and Flame 165 (2016) 125-136.

[43] P. Dagaut, J.-C. Boettner, M. Cathonnet, Methane oxidation: experimental and kinetic modeling study, Combustion science and technology 77 (1-3) (1991) 127-148.

[44] T. L. Le Cong, P. Dagaut, Experimental and detailed kinetic modeling of the oxidation of methane and methane/syngas mixtures and effect of carbon dioxide addition, Combustion Science and Technology 180 (1011) (2008) 2046-2091.

[45] Y. Tan, P. Dagaut, M. Cathonnet, J.-C. Boettner, Acetylene oxida- 
tion in a jsr from 1 to 10 atm and comprehensive kinetic modeling, Combustion science and technology 102 (1-6) (1994) 21-55.

[46] A. Fomin, T. Zavlev, V. A. Alekseev, A. A. Konnov, I. Rahinov, S. Cheskis, Intracavity laser absorption spectroscopy study of HCO radicals during methane to hydrogen conversion in very rich flames, Energy \& Fuels 29 (9) (2015) 6146-6154.

[47] A. Fomin, T. Zavlev, V. A. Alekseev, I. Rahinov, S. Cheskis, A. A. Konnov, Experimental and modelling study of ${ }^{1} \mathrm{CH}_{2}$ in premixed very rich methane flames, Combustion and Flame 171 (2016) 198-210.

[48] M. C. Krejci, O. Mathieu, A. J. Vissotski, S. Ravi, T. G. Sikes, E. L. Petersen, K. Alan, W. Metcalfe, H. J. Curran, et al., Laminar flame speed and ignition delay time data for the kinetic modeling of hydrogen and syngas fuel blends, Journal of Engineering for Gas Turbines and Power 135 (2) (2013) 021503.

[49] O. Park, P. S. Veloo, H. Burbano, F. N. Egolfopoulos, Studies of premixed and non-premixed hydrogen flames, Combustion and Flame 162 (4) (2015) 1078-1094.

[50] S. Voss, S. Hartl, C. Hasse, Determination of laminar burning velocities for lean low calorific $\mathrm{H}_{2} / \mathrm{N}_{2}$ and $\mathrm{H}_{2} / \mathrm{CO} / \mathrm{N}_{2}$ gas mixtures, International Journal of Hydrogen Energy 39 (34) (2014) 19810-19817.

[51] V. A. Alekseev, A. A. Konnov, Data consistency of the burning velocity measurements using the heat flux method: Hydrogen flames, Combustion and Flame 194 (2018) 28-36. 
[52] H. Sun, S. Yang, G. Jomaas, C. Law, High-pressure laminar flame speeds and kinetic modeling of carbon monoxide/hydrogen combustion, Proceedings of the Combustion Institute 31 (1) (2007) 439-446.

[53] B. Lohöfener, E. Roungos, S. Voss, D. Trimis, Burning velocities of low calorific value hydrogen and carbon monoxide gas mixtures, in: 2nd Heat Flux Burner Workshop, Warsaw University of Technology, Poland, 2012.

[54] V. R. Kishore, M. Ravi, A. Ray, Adiabatic burning velocity and cellular flame characteristics of $\mathrm{H}_{2}-\mathrm{CO}-\mathrm{CO}_{2}$-air mixtures, Combustion and flame 158 (11) (2011) 2149-2164.

[55] A. A. Konnov, I. V. Dyakov, J. de Ruyck, Nitric oxide formation in premixed flames of $\mathrm{H}_{2}+\mathrm{CO}+\mathrm{CO}_{2}$ and air, Proceedings of the Combustion Institute 29 (2) (2002) 2171-2177.

[56] L. Sileghem, V. Alekseev, J. Vancoillie, E. Nilsson, S. Verhelst, A. Konnov, Laminar burning velocities of primary reference fuels and simple alcohols, Fuel 115 (2014) 32-40.

[57] A. A. Konnov, I. Dyakov, Nitrous oxide conversion in laminar premixed flames of $\mathrm{CH}_{4}+\mathrm{O}_{2}+\mathrm{Ar}$, Proceedings of the Combustion Institute 32 (1) (2009) 319-326.

[58] O. Park, P. S. Veloo, N. Liu, F. N. Egolfopoulos, Combustion characteristics of alternative gaseous fuels, Proceedings of the Combustion Institute 33 (1) (2011) 887-894. 
[59] R. T. E. Hermanns, Laminar burning velocities of methane-hydrogenair mixtures, Ph.D. thesis, Technische Universiteit Eindhoven (2007). doi:10.6100/IR630126.

[60] E. J. Nilsson, A. van Sprang, J. Larfeldt, A. A. Konnov, The comparative and combined effects of hydrogen addition on the laminar burning velocities of methane and its blends with ethane and propane, Fuel 189 (2017) 369-376.

[61] F. Coppens, J. De Ruyck, A. A. Konnov, The effects of composition on burning velocity and nitric oxide formation in laminar premixed flames of $\mathrm{CH}_{4}+\mathrm{H}_{2}+\mathrm{O}_{2}+\mathrm{N}_{2}$, Combustion and Flame 149 (4) (2007) 409-417.

[62] E. Hu, Z. Huang, J. He, J. Zheng, H. Miao, Measurements of laminar burning velocities and onset of cellular instabilities of methanehydrogen-air flames at elevated pressures and temperatures, International Journal of Hydrogen Energy 34 (13) (2009) 5574 - 5584.

[63] O. Park, P. S. Veloo, F. N. Egolfopoulos, Flame studies of $\mathrm{c}_{2}$ hydrocarbons, Proceedings of the Combustion Institute 34 (1) (2013) 711-718.

[64] P. Oßwald, R. Whitside, J. Schäffer, M. Köhler, An experimental flow reactor study of the combustion kinetics of terpenoid jet fuel compounds: Farnesane, p-menthane and p-cymene, Fuel 187 (2017) 43 50.

[65] C. Olm, I. G. Zsély, T. Varga, H. J. Curran, T. Turányi, Comparison 
of the performance of several recent syngas combustion mechanisms, Combustion and Flame 162 (5) (2015) 1793-1812.

[66] Z. Hong, R. D. Cook, D. F. Davidson, R. K. Hanson, A shock tube study of $\mathrm{OH}+\mathrm{H}_{2} \mathrm{O}_{2} \rightarrow \mathrm{H}_{2} \mathrm{O}+\mathrm{HO}_{2}$ and $\mathrm{H}_{2} \mathrm{O}_{2}+\mathrm{M} \rightarrow 2 \mathrm{OH}+\mathrm{M}$ using laser absorption of $\mathrm{H}_{2} \mathrm{O}$ and $\mathrm{OH}$, The Journal of Physical Chemistry A 114 (18) (2010) 5718-5727.

[67] A. Laskin, H. Wang, On initiation reactions of acetylene oxidation in shock tubes: a quantum mechanical and kinetic modeling study, Chemical Physics Letters 303 (1) (1999) 43-49.

[68] P.-F. Lee, H. Matsui, W.-Y. Chen, N.-S. Wang, Production of H and $\mathrm{O}\left({ }^{3} \mathrm{P}\right)$ atoms in the reaction of $\mathrm{CH}_{2}$ with $\mathrm{O}_{2}$, The Journal of Physical Chemistry A 116 (37) (2012) 9245-9254.

[69] C. Vinckier, W. Debruyn, Temperature dependence of the reactions of methylene with oxygen atoms, oxygen, and nitric oxide, Journal of physical chemistry 83 (16) (1979) 2057-2062.

[70] M. A. Blitz, C. Kappler, M. J. Pilling, P. W. Seakins, ${ }^{3} \mathrm{CH}_{2}+\mathrm{O}_{2}$ : Kinetics and product channel branching ratios, Zeitschrift für Physikalische Chemie 225 (9-10) (2011) 957-967.

[71] G. Smith, Y. Tao, H. Wang, Foundational fuel chemistry model version 1.0 (FFCM-1), http://nanoenergy.stanford.edu/ffcm1 (2016).

[72] C. F. Goldsmith, L. B. Harding, Y. Georgievskii, J. A. Miller, S. J. Klippenstein, Temperature and pressure-dependent rate coefficients for 
the reaction of vinyl radical with molecular oxygen, The Journal of Physical Chemistry A 119 (28) (2015) 7766-7779.

[73] T. Kathrotia, U. Riedel, J. Warnatz, A numerical study on the relation of $\mathrm{oh}^{*}, \mathrm{ch}^{*}$, and $\mathrm{c} 2^{*}$ chemiluminescence and heat release in premixed methane flames, in: Proceedings of the European combustion Meeting, Citeseer, 2009, pp. 1-5.

[74] T. Kathrotia, M. Fikri, M. Bozkurt, M. Hartmann, U. Riedel, C. Schulz, Study of the $\mathrm{h}+\mathrm{o}+\mathrm{m}$ reaction forming oh: Kinetics of oh chemiluminescence in hydrogen combustion systems, Combustion and Flame 157 (7) (2010) 1261-1273.

[75] B. Ruscic, D. H. Bross, Active Thermochemical Tables (ATcT) values based on version 1.122 of the Thermochemical Network, available at ATcT.anl.gov.

[76] P. Glarborg, J. A. Miller, B. Ruscic, S. J. Klippenstein, Modeling nitrogen chemistry in combustion, Progress in Energy and Combustion Science 67 (2018) 31-68.

[77] Z. Hong, D. F. Davidson, R. K. Hanson, An improved $\mathrm{H}_{2} / \mathrm{O}_{2}$ mechanism based on recent shock tube/laser absorption measurements, Combustion and Flame 158 (4) (2011) 633-644.

[78] A. Kéromnès, W. K. Metcalfe, K. A. Heufer, N. Donohoe, A. K. Das, C.-J. Sung, J. Herzler, C. Naumann, P. Griebel, O. Mathieu, M. C. Krejci, E. L. Petersen, W. J. Pitz, H. J. Curran, An experimental and detailed chemical kinetic modeling study of hydrogen and syngas 
mixture oxidation at elevated pressures, Combustion and Flame 160 (6) (2013) $995-1011$.

[79] J. Troe, V. Ushakov, The dissociation/recombination reaction $\mathrm{CH}_{4}(+$ $\mathrm{M}) \leftrightarrow \mathrm{CH}_{3}+\mathrm{H}(+\mathrm{M}):$ A case study for unimolecular rate theory, The Journal of chemical physics 136 (21) (2012) 214309.

[80] N. Faßheber, G. Friedrichs, P. Marshall, P. Glarborg, Glyoxal oxidation mechanism: implications for the reactions $\mathrm{HCO}+\mathrm{O}_{2}$ and $\mathrm{OCHCHO}+$ $\mathrm{HO}_{2}$, The Journal of Physical Chemistry A 119 (28) (2015) 7305-7315.

[81] S. J. Klippenstein, J. A. Miller, L. B. Harding, Resolving the mystery of prompt $\mathrm{CO}_{2}$ : The $\mathrm{HCCO}+\mathrm{O}_{2}$ reaction, Proceedings of the Combustion Institute 29 (1) (2002) 1209-1217.

[82] A. W. Jasper, S. J. Klippenstein, L. B. Harding, B. Ruscic, Kinetics of the reaction of methyl radical with hydroxyl radical and methanol decomposition, The Journal of Physical Chemistry A 111 (19) (2007) $3932-3950$.

[83] A. W. Jasper, S. J. Klippenstein, L. B. Harding, Theoretical rate coefficients for the reaction of methyl radical with hydroperoxyl radical and for methylhydroperoxide decomposition, Proceedings of the Combustion Institute 32 (1) (2009) 279-286.

[84] Z. Xu, P. Raghunath, M. Lin, Ab initio chemical kinetics for the ch3+ o (3p) reaction and related isomerization-decomposition of ch3o and ch2oh radicals, The Journal of Physical Chemistry A 119 (28) (2015) $7404-7417$. 
[85] S. Dóbé, T. Bérces, I. Szilágyi, Kinetics of the reaction between methoxyl radicals and hydrogen atoms, Journal of the Chemical Society, Faraday Transactions 87 (15) (1991) 2331-2336.

[86] S. Wang, D. F. Davidson, R. K. Hanson, Improved shock tube measurement of the $\mathrm{CH}_{4}+\mathrm{Ar}=\mathrm{CH}_{3}+\mathrm{H}+\mathrm{Ar}$ rate constant using UV cavity-enhanced absorption spectroscopy of $\mathrm{CH}_{3}$, The Journal of Physical Chemistry A 120 (28) (2016) 5427-5434.

[87] P. Frank, K. Bhaskaran, T. Just, Acetylene oxidation: The reaction $\mathrm{c} 2 \mathrm{~h} 2+\mathrm{o}$ at high temperatures, in: Symposium (International) on Combustion, Vol. 21, Elsevier, 1988, pp. 885-893.

[88] J. P. Senosiain, S. J. Klippenstein, J. A. Miller, The reaction of acetylene with hydroxyl radicals, The Journal of Physical Chemistry A 109 (27) (2005) 6045-6055.

[89] J. A. Miller, S. J. Klippenstein, The $\mathrm{H}+\mathrm{C}_{2} \mathrm{H}_{2}(+\mathrm{M}) \rightleftharpoons \mathrm{C}_{2} \mathrm{H}_{3}(+\mathrm{M})$ and $\mathrm{H}+\mathrm{C}_{2} \mathrm{H}_{2}(+\mathrm{M}) \rightleftharpoons \mathrm{C}_{2} \mathrm{H}_{5}(+\mathrm{M})$ reactions: Electronic structure, variational transition-state theory, and solutions to a two-dimensional master equation, Physical Chemistry Chemical Physics 6 (6) (2004) $1192-1202$.

[90] X. Li, A. W. Jasper, J. Zádor, J. A. Miller, S. J. Klippenstein, Theoretical kinetics of $\mathrm{O}+\mathrm{C}_{2} \mathrm{H}_{4}$, Proceedings of the Combustion Institute 36 (1) (2017) 219-227.

[91] E. Ranzi, A. Frassoldati, R. Grana, A. Cuoci, T. Faravelli, A. Kelley, C. Law, Hierarchical and comparative kinetic modeling of laminar 
flame speeds of hydrocarbon and oxygenated fuels, Progress in Energy and Combustion Science 38 (4) (2012) 468-501.

[92] Y. Li, C.-W. Zhou, K. P. Somers, K. Zhang, H. J. Curran, The oxidation of 2-butene: A high pressure ignition delay, kinetic modeling study and reactivity comparison with isobutene and 1-butene, Proceedings of the Combustion Institute 36 (1) (2017) 403-411.

[93] D. G. Goodwin, H. K. Moffat, R. L. Speth, Cantera: An object-oriented software toolkit for chemical kinetics, thermodynamics, and transport processes, http://www.cantera.org, version 2.3.0 (11 2017). doi:10.5281/zenodo.170284.

[94] E. Agelidou, T. Monz, A. Huber, M. Aigner, Experimental investigation of an inverted brayton cycle micro gas turbine for chp application, in: ASME Turbo Expo 2017: Turbomachinery Technical Conference and Exposition, no. GT2017-64490, American Society of Mechanical Engineers, 2017, p. V008T26A023.

[95] W.-D. Hsieh, R.-H. Chen, T.-L. Wu, T.-H. Lin, Engine performance and pollutant emission of an si engine using ethanol-gasoline blended fuels, Atmospheric Environment 36 (3) (2002) 403-410.

[96] J. J. Scire Jr, R. A. Yetter, F. L. Dryer, Flow reactor studies of methyl radical oxidation reactions in methane-perturbed moist carbon monoxide oxidation at high pressure with model sensitivity analysis, International Journal of Chemical Kinetics 33 (2) (2001) 75-100. 
[97] Z. Hong, D. F. Davidson, K.-Y. Lam, R. K. Hanson, A shock tube study of the rate constants of $\mathrm{HO}_{2}$ and $\mathrm{CH}_{3}$ reactions, Combustion and Flame 159 (10) (2012) 3007-3013.

[98] N. Srinivasan, J. Michael, L. Harding, S. Klippenstein, Experimental and theoretical rate constants for $\mathrm{CH}_{4}+\mathrm{O}_{2} \rightarrow \mathrm{CH}_{3}+\mathrm{HO}_{2}$, Combustion and flame 149 (1-2) (2007) 104-111.

[99] D. Davidson, R. Hanson, C. Bowman, Revised values for the rate coefficients of ethane and methane decomposition, International journal of chemical kinetics 27 (3) (1995) 305-308.

[100] W. Shaub, D. Hsu, T. Burks, M. Lin, Dynamics and mechanisms of $\mathrm{CO}$ production from the reactions of $\mathrm{CH}_{2}$ radicals with $\mathrm{O}(3 \mathrm{P})$ and $\mathrm{O}_{2}$, in: Symposium (International) on Combustion, Vol. 18, Elsevier, 1981, pp. $811-818$.

[101] A. O. Langford, H. Petek, C. B. Moore, Collisional removal of $\mathrm{CH}_{2}\left({ }^{1} \mathrm{~A}_{1}\right)$ : Absolute rate constants for atomic and molecular collisional partners at $295 \mathrm{k}$, The Journal of Chemical Physics 78 (11) (1983) 6650-6659.

[102] G. Hancock, V. Haverd, A time-resolved ftir emission study of the gas phase removal processes of $\mathrm{CH}_{2}\left(\mathrm{X}^{3} \mathrm{~B}_{1}\right)$ and $\mathrm{CH}_{2}\left(\mathrm{a}^{1} \mathrm{~A}_{1}\right)$ in collisions with $\mathrm{O}_{2}$, Chemical physics letters 372 (1-2) (2003) 288-294. 